\title{
Symptomatic Therapy and Rehabilitation in Primary Progressive Multiple Sclerosis
}

\author{
Fary Khan, ${ }^{1}$ Bhasker Amatya, ${ }^{2}$ and Lynne Turner-Stokes ${ }^{3}$ \\ ${ }^{1}$ Department of Medicine, Dentistry and Health Sciences at The University of Melbourne, Royal Melbourne Hospital and \\ Western Health, Rehabilitation Service—Royal Melbourne Hospital, Poplar Road, Parkville, Melbourne, VIC 3052, Australia \\ ${ }^{2}$ Department of Rehabilitation Medicine, Royal Melbourne Hospital, 34-54 Poplar Road Parkville, Melbourne, VIC 3052, Australia \\ ${ }^{3}$ Regional Rehabilitation Unit, Northwick Park Hospital, Watford Road, Harrow, Middlesex HA1 3UJ, UK \\ Correspondence should be addressed to Fary Khan, fary.khan@mh.org.au
}

Received 19 May 2011; Accepted 13 July 2011

Academic Editor: Peter van den Bergh

Copyright ( $\odot 2011$ Fary Khan et al. This is an open access article distributed under the Creative Commons Attribution License, which permits unrestricted use, distribution, and reproduction in any medium, provided the original work is properly cited.

Multiple sclerosis (MS) is an autoimmune inflammatory demyelinating disease of the central nervous system and a major cause of chronic neurological disability in young adults. Primary progressive MS (PPMS) constitutes about 10\% of cases, and is characterized by a steady decline in function with no acute attacks. The rate of deterioration from disease onset is more rapid than relapsing remitting and secondary progressive MS types. Multiple system involvement at onset and rapid early progression have a worse prognosis. PPMS can cause significant disability and impact on quality of life. Recent studies are biased in favour of relapsing remitting patients as treatment is now available for them and they are more likely to be seen at MS clinics. Since prognosis for PPMS is worse than other types of MS, the focus of rehabilitation is on managing disability and enhancing participation, and application of a "neuropalliative" approach as the disease progresses. This chapter presents the symptomatic treatment and rehabilitation for persons with MS, including PPMS. A multidisciplinary approach optimizes the intermediate and long-term medical, psychological and social outcomes in this population. Restoration and maintenance of functional independence and societal reintegration, and issues relating to quality of life are addressed in rehabilitation processes.

\section{Background}

Multiple sclerosis (MS) is a chronic inflammatory demyelinating disease of the central nervous system (CNS) affecting about 2.5 million persons' worldwide [1]. It is the commonest cause of chronic neurological disability in young adults. MS is complex and the exact pathogenesis is unclear. The various disease courses in persons with MS (pwMS) are shown in Box 1. One recent survey of 878 persons with primary progressive MS (PPMS) [2] were found to have a shorter median time to death from onset and a higher relative risk of dying despite the fact that persons with PPMS live for years with many disabilities that can cause limitation in function and restriction in participation and impact quality of life (QoL) [3].

The natural history of PPMS is less well known compared with other MS disease courses. Primary progressive MS occurs in approximately $10 \%$ of pwMS and is primarily progressive from onset. Approximately $<5 \%$ of pwMS may present with a progressive course although these patients also experience occasional attacks, the progressive relapsing MS type (PRMS) (see Box 1). The diagnostic criteria for PPMS are shown in Table 1. It is thought to be different genetically from the relapsing remitting MS (RRMS) and in MRI behaviour from secondary progressive MS type (SPMS) $[4,5]$. In PPMS, the paucity of MRI detectable disease activity is in contrast with the observed accumulation of irreversible disability [6]. Quantitative MRI studies [7] have highlighted the role of brain tissue damage outside T2 visible lesions in the pathophysiology of PPMS.Kutzelnigg et al. [8] showed that diffuse white matter injury and cortical demyelination were hallmarks of progressive MS, occurring on a background of a global "low burning" inflammatory response with focal lesion load. The contribution of cord damage to the severity and evolution of PPMS has also been evident in several MRI studies $[9,10]$. 
Relapsing remitting MS (RRMS) occurs in $80 \%$ of MS cases at onset. It is characterized by relapses, which evolve over days to weeks, with full recovery or with sequelae and residual deficit upon recovery. Between attacks, the patient is neurologically and symptomatically stable.

Secondary progressive MS (SPMS) may begin as RRMS, but at some point, the attack rate reduces and the course shows steady deterioration in function unrelated to acute attacks.

Primary progressive MS (PPMS) accounts for 10\% of cases at disease onset and is characterized by steady decline in function from the beginning without acute attacks. These patients have a more even sex distribution, tend to have later age of onset, and may have a worse prognosis for ultimate disability compared with those with RRMS.

Progressive relapsing MS (PRMS) $(<5 \%)$ also begins with a progressive course although these patients also experience occasional attacks.

Box 1: Types of MS. Adapted from Polman et al. [11].

TABLE 1: McDonald criteria for MS.

\begin{tabular}{|c|c|c|}
\hline Clinical (Attacks) & $\begin{array}{l}\text { Objective } \\
\text { lesions }\end{array}$ & Additional requirements to make a diagnosis \\
\hline Two or more & $\begin{array}{l}\text { Two or more, or } \\
\text { objective clinical } \\
\text { evidence of one } \\
\text { lesion with } \\
\text { reasonable } \\
\text { historical } \\
\text { evidence of a } \\
\text { prior attack }\end{array}$ & None \\
\hline Two or more & One & $\begin{array}{l}\text { Dissemination in space, demonstrated by: } \\
\text { one or more T2 lesion in at least } 2 \text { of } 4 \text { MS-typical regions of the CNS (periventricular, } \\
\text { juxtacortical, infratentorial, or spinal cord) or await a further clinical attack implicating a } \\
\text { different CNS site }\end{array}$ \\
\hline One & Two or more & $\begin{array}{l}\text { Dissemination in time, demonstrated by: } \\
\text { simultaneous presence of asymptomatic gadolinium-enhancing and nonenhancing lesions at } \\
\text { any time; or A new T2 and/or gadolinium-enhancing lesion(s) on follow-up MRI, irrespective } \\
\text { of its timing with reference to a baseline scan or await a second clinical attack }\end{array}$ \\
\hline $\begin{array}{l}\text { One (clinically } \\
\text { isolated syndrome) }\end{array}$ & One & $\begin{array}{l}\text { Dissemination in space and time, demonstrated by: } \\
\text { for DIS: } \\
\text { one or more T2 lesion in at least } 2 \text { of } 4 \text { MS-typical regions of the CNS (periventricular, } \\
\text { juxtacortical, infratentorial, or spinal cord) or await a second clinical attack implicating a } \\
\text { different CNS site and For DIT: } \\
\text { simultaneous presence of asymptomatic gadolinium-enhancing and nonenhancing lesions at } \\
\text { any time or a new T2 and/or gadolinium-enhancing lesion(s) on follow-up MRI, irrespective } \\
\text { of its timing with reference to a baseline scan or await a second clinical attack }\end{array}$ \\
\hline $\begin{array}{l}\text { Insidious } \\
\text { neurological } \\
\text { progression } \\
\text { suggestive of MS } \\
\text { (PPMS) }\end{array}$ & & $\begin{array}{l}\text { One year of disease progression (retrospectively or prospectively determined) plus } 2 \text { of } 3 \text { of the } \\
\text { following criteria: } \\
\text { (1) evidence for DIS in the brain based on one or more T2 lesions in the MS-characteristic } \\
\text { (periventricular, juxtacortical, or infratentorial) regions, } \\
\text { (2) evidence for DIS in the spinal cord based on tow or more T2 lesions in the cord } \\
\text { (3) positive CSF (isoelectric focusing evidence of oligoclonal bands and/or elevated IgG index) }\end{array}$ \\
\hline
\end{tabular}

MS: multiple sclerosis; CNS: central nervous system; MRI: magnetic resonance imaging; DIS: dissemination in space; DIT: dissemination in time; PPMS: primary progressive multiple sclerosis; CSF: cerebrospinal fluid; IgG: immunoglobulin G. (Adapted from Polman et al. [12].)

The overall female preponderance in MS is less applicable to PPMS. The rate of deterioration from disease onset in PPMS is more rapid, with higher relative mortality than other MS types [13]. Those with shorter time from onset to disability and those with involvement of three or more neurological symptoms at onset have a worse prognosis [14]. However prognosis in PPMS is not dependent on age, gender, or type of neurological system involvement at onset.
A minority of people with PPMS can have a distinct relapse even decades after onset of progressive deterioration [14].

Recent nonpopulation-based studies are biased towards RRMS as treatment is now available for reducing the number of relapses and delaying disease progression, so they are more likely to be reviewed at MS clinics. All suggested drug treatments for PPMS are empiric as there is no convincing trial evidence of effectiveness for disease 
Interactions between the components of ICF

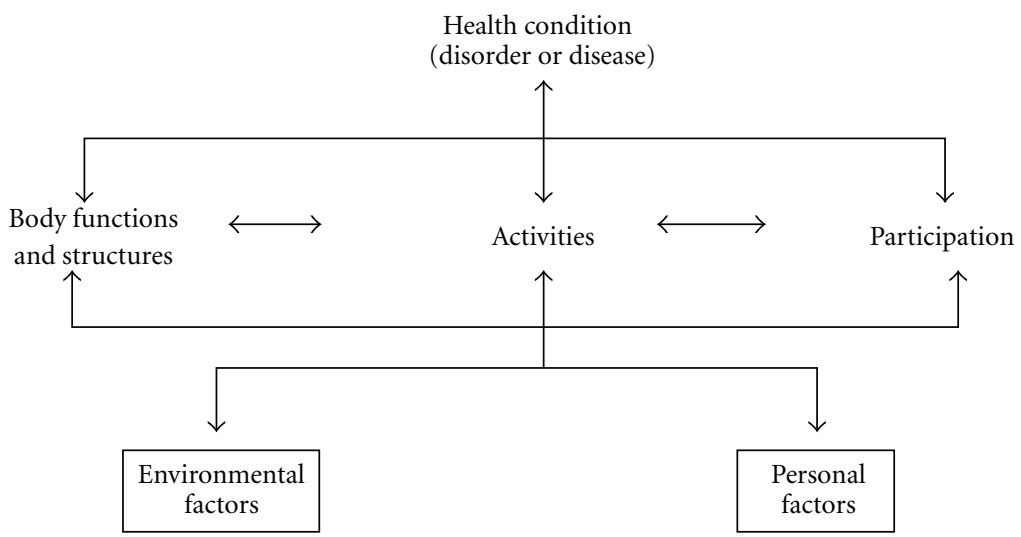

FIGURE 1: Components of international classification of functioning disability and health. (Printed with permission: WHO-ICF [15].)

(i) Individualized patient centred treatment plan, with patient actively participating.

(ii) Prioritized goal setting through an interdisciplinary process.

(iii) Active patient participation to achieve set goals.

(iv) Goals should result in improvement in patients' personal potential.

(v) Outcomes should demonstrate reduction in impairments and improvement in, activity and participation.

Box 2: Subcomponents of comprehensive rehabilitation. Adapted from: Steins et al. [16].

modifying therapy [17]. An individual with PPMS, therefore, has limited drug therapy options and may benefit from a symptomatic and supportive rehabilitation approach aimed at reducing symptoms and limitations at the level of activity and participation.

Studies of pwMS have identified a range of impairments, limitations in activity (disability), and restriction in participation using the World Health Organization's International Classification of Functioning, Health, and Disability (ICF) Figure 1 [15, 18, 19]. These ICF domains have complex interactions and need evaluation and management through holistic interventions, which include personal and environmental factors. Recent MS expert consensus identified and recommended the "Core" set (minimum data set) of ICF categories for pwMS for comprehensive multidisciplinary assessments in the domains of body function, body structure, activities, and participation and environmental factors [18] (Tables 2-3). Much of the clinical focus has traditionally been on the physical aspects of MS but improved understanding of MS indicates involvement of multiple systems (cognition, memory, and emotional control). The combined effect of these impairments in a pwMS leads to greater disability than the sum of the individual impairments together. This may explain why some pwMS may not perform as well as expected [20].

\section{Rehabilitation}

Rehabilitation is defined as a problem solving educational process aimed at reducing disability and limitation in par- ticipation [21]. Rehabilitation interventions comprise expert MD assessments evaluated through appropriate outcome measures [22] using functional goal-oriented approaches such as clinical pathways [23] to target patient priorities [24]. Goal setting is an integral part of rehabilitation, as it encourages participants to set their own goals and priorities, and supports team communication and coordination. The key subcomponents and phases of the rehabilitation process [16] are shown in Boxes 2 and 3.

Existing clinical guidelines and frameworks [26, 27] for PPMS recommend comprehensive, flexible coordinated multidisciplinary (MD) care and appropriate followup, education, and support for patients and carers to address the limitations in activity and participation levels. Key issues for those severely affected include respite, community and/or long-term care, and community mobility. Early referral for rehabilitation enables strategies to restore recent functional deterioration [26]. In those severely affected, rehabilitation input can provide a modified environment and adaptive equipment to restore some functional independence. Caregiver education and support can reduce the burden of care. Rehabilitation can address QoL issues and direct care with other health professionals [28]. Importantly, "crisis management" should be avoided, planned management of disability and deficits should be anticipated (over time), and appropriate mechanisms that accommodate and facilitate functional independence provided. Some of the challenges to MS rehabilitation are shown in Box 4. 
(i) Evaluation-identification and quantifying effects of disablement (limitation in activity and participation) — mediators for adaptive capacity that can be targeted foci for therapy.

(ii) Treatments_-arrest the pathophysiologic processes causing tissue injury.

(iii) Therapeutic exercise-focuses on enhancement of organ performance.

(iv) Task reacquisition-emphasizes total body adaptive techniques.

(v) Environmental modification-directs effort towards environmental enhancement (physical, psychological, social, and Political) to improve participation.

Box 3: Phases in rehabilitation process. Adapted from: Steins et al. [16].

(i) MS is dynamic with a complex moving target of deficits.

(ii) Unpredictable disease progression and lesion distribution makes it difficult for the patient to adjust and use compensatory strategies.

(iii) Covert symptoms (fatigue, diplopia) can be disabling but not visible to others.

(iv) Profound sense of vulnerability, loss of control, and grieving underlies the coping process.

Box 4: Challenges in MS rehabilitation.

\section{Evidence for MS Rehabilitation}

A recent systematic review supports the effectiveness of MD rehabilitation programs in inpatient and ambulatory settings in terms of improvements in activity (disability) and participation [29]. Although there is evidence for some unidisciplinary rehabilitation interventions for pwMS, such as physical therapy [30], the evidence for othersoccupational therapy [31] and psychological therapies [32] is less compelling. There is reasonable evidence to support cognitive behaviour approaches for depression in helping people adjust to, and cope with, having MS [33]. A recent randomized controlled trial showed the duration of benefit of rehabilitation in reducing disability persists for about 12 months [34] but not the positive effects on QoL and emotional well-being. Effects on QoL are often difficult to quantify in chronic conditions because of "response shift" or the change in internal values, or conceptualization of QoL, so that pwMS may reassess their perceived limitations of daily living and reset goals and consider the impact of their MS less marked than they thought formerly [35]. More studies are needed to assess impact of rehabilitation on QoL and to understand the response shift phenomenon in the MS population.

Further, in addition to randomized controlled trial (RCT) methodology, a clinical practice improvement approach has also been applied to an inpatient MS cohort to understand the complex interplay of patient and process factors and impact on functional outcomes in rehabilitation for pwMS. In a pilot project $(n=24)$ [36], more than half of pwMS had moderate to severe fatigue, deficits in motor function and mood causing significant functional limitation, and two thirds required specialized nursing (e.g., continence care). Complexity of intervention was measured using the Northwick Park therapy dependency assessment (NPTDA) [37], which showed moderate dependency in physical, cognitive, and psychosocial domains. The NPTDA scores for these pwMS correlated strongly with FIM motor scores
(Spearman rho -0.80) and Barthel index (rho -0.83) [36]. Further prospective studies are planned using appropriate tools to understand the "black box" of rehabilitation and the complex inter relationships of factors which impact function in this population.

Khan et al. [38] examined outcomes following inpatient rehabilitation episodes $(n=1010)$ for pwMS using the Australian Rehabilitation Outcomes Centre Database. The majority of patients were female and following rehabilitation discharged to the community. Improvement in function was assessed using the functional independence measure (FIM), with subclasses of pwMS based on motor FIM scores for severity in functional limitation. Authors reported significant functional improvement $(P=0.001)$ with rehabilitation in most MS groups, with year to year trend towards reducing hospital length of stay and FIM efficiency although these did not reach significance.

\section{Neuropalliative Approach in PPMS}

Since prognosis for PPMS is worse than other types of MS, the focus of rehabilitation is on managing disability and enhancing participation, and as disease progresses applying a "neuropalliative approach" [25]. The UK guidelines for managing long-term neurological conditions (LTNC) [39] are relevant to PPMS as they explore interaction between specialist neurology, rehabilitation, and palliative care services and how they work together to provide long-term support for people with LTNC and their carers. The key skills in neuropalliative care are shown in Table 4 [25]. Neurologists assess, diagnose, and manage disease, and the palliative care physicians' manage distressing symptoms (nausea, vomiting, and breathlessness), support and counsel the person and family, end-of-life issues, and provide advance care planning. Rehabilitation physicians contribute to care by managing disability and provide adaptive aids (mobility and communication), procedures for spasticity management (botulinum 
TABLE 2: International classification of functioning, disability, and health (ICF) categories for the components: body "function" and body "structure" included in the "core" set for persons with MS for comprehensive multidisciplinary assessments.

\begin{tabular}{|c|c|}
\hline ICF code & ICF category title \\
\hline \multicolumn{2}{|c|}{ Body function } \\
\hline B122 & global psychosocial functions \\
\hline B130 & energy and drive functions \\
\hline B144 & memory function \\
\hline B147 & psychomotor function \\
\hline B126 & temperament and personality functions \\
\hline B152 & emotional functions \\
\hline B164 & higher level cognitive functions \\
\hline B140 & attention function \\
\hline B160 & thought functions \\
\hline B114 & orientation functions \\
\hline B210 & seeing function \\
\hline B265 & touch function \\
\hline B260 & proprioceptive function \\
\hline B280 & sensation of pain \\
\hline B235 & vestibular functions \\
\hline B320 & articulation functions \\
\hline B330 & fluency and rhythm of speech functions \\
\hline B310 & voice functions \\
\hline B455 & exercise tolerance functions \\
\hline B435 & immunological system functions \\
\hline B525 & defecation function \\
\hline B640 & sexual functions \\
\hline B620 & urination functions \\
\hline B760 & control of voluntary movement functions \\
\hline B750 & motor reflex functions \\
\hline B730 & muscle power functions \\
\hline B735 & muscle tone functions \\
\hline B755 & involuntary movement reaction functions \\
\hline B770 & gait pattern functions \\
\hline B710 & mobility of joint functions \\
\hline B780 & sensations related to muscle and movement functions \\
\hline B715 & stability of joint functions \\
\hline \multicolumn{2}{|c|}{ Body structure } \\
\hline S110 & structure of brain \\
\hline S120 & structures spinal cord and related \\
\hline S610 & structure of urinary system \\
\hline S720d & structure of shoulder region \\
\hline S730 & structure of upper extremity \\
\hline S750 & structure of lower extremity \\
\hline S760 & structure of trunk \\
\hline
\end{tabular}

(Adapted from Khan and Pallant [18].)

toxin and phenol), and pain and behaviour management. As disease progresses goal posts change and rehabilitation and palliative approaches can overlap, that is, "neuropalliation". Many issues in PPMS can be managed by closer collaboration and cross referral between the above specialties [40, 41]. The life circles diagram Figure 2 [25] shows the overlap between roles of neurology, palliative care, and rehabilitation physicians which are relevant to people with PPMS. 
TABLE 3: International classification of functioning, disability and health (ICF) categories for the components: "activities and participation" and "environmental factors" included in the "core" set for persons with MS for comprehensive multidisciplinary assessments.

\begin{tabular}{|c|c|}
\hline ICF code & ICF category title \\
\hline \multicolumn{2}{|c|}{ Activities and participation } \\
\hline D160 & focusing attention \\
\hline D172 & calculating \\
\hline D175 & solving problems \\
\hline D220 & undertaking multiple tasks \\
\hline D240 & handling stress and other psychological demands \\
\hline D163 & thinking \\
\hline D166 & reading \\
\hline D177 & making decisions \\
\hline D230 & carrying out daily routine \\
\hline D210 & undertaking a single task \\
\hline D330 & speaking \\
\hline D350 & conversation \\
\hline D355 & discussion \\
\hline D345 & writing messages \\
\hline D315 & communicating with-receiving-nonverbal messages \\
\hline D310 & communicating with-receiving-spoken messages \\
\hline D360 & using communication devices and techniques \\
\hline D335 & producing nonverbal messages \\
\hline D325 & communicating with-receiving-written messages \\
\hline D415 & maintaining a body position \\
\hline D420 & transferring oneself \\
\hline D445 & hand and arm use \\
\hline D450 & walking \\
\hline D455 & moving around \\
\hline D410 & changing basic body position \\
\hline D430 & lifting and carrying objects \\
\hline D440 & fine hand use \\
\hline D460 & moving around in different locations \\
\hline D456 & moving around using equipment \\
\hline D470 & using transportation \\
\hline D475 & driving \\
\hline D510 & washing oneself \\
\hline D530 & toileting \\
\hline D540 & dressing \\
\hline D550 & eating \\
\hline D520 & caring for body parts \\
\hline D560 & drinking \\
\hline D570 & looking after one's health \\
\hline D630 & preparing meals \\
\hline D640 & doing housework \\
\hline D650 & caring for household objects \\
\hline D620 & acquisition of goods and services \\
\hline D770 & intimate relationships \\
\hline D710 & basic interpersonal interactions \\
\hline D720 & complex interpersonal interactions \\
\hline
\end{tabular}


Table 3: Continued.

\begin{tabular}{|c|c|}
\hline ICF code & ICF category title \\
\hline D740 & formal relationships \\
\hline D760 & family relationships \\
\hline D750 & informal social relationships \\
\hline D850 & remunerative employment \\
\hline D845 & acquiring keeping and terminating a job \\
\hline D870 & economic self sufficiency \\
\hline D825 & vocational training \\
\hline D855 & nonremunerative employment \\
\hline D860 & basic economic transactions \\
\hline D920 & recreation and leisure \\
\hline D910 & community life \\
\hline D930 & religion and spirituality \\
\hline \multicolumn{2}{|c|}{ Environmental Factors } \\
\hline E120 & $\begin{array}{l}\text { products or technology for personal indoor/outdoor } \\
\text { mobility and transportation }\end{array}$ \\
\hline E135 & products and technology for employment \\
\hline E115 & products or technology for personal use in daily living \\
\hline E125 & products and technology for communication \\
\hline E130 & products and technology for education \\
\hline E155 & $\begin{array}{l}\text { design, construction, building products, and technology } \\
\text { of buildings for private use }\end{array}$ \\
\hline E150 & $\begin{array}{l}\text { design, construction, building products, and technology } \\
\text { of buildings for public use }\end{array}$ \\
\hline E110 & products or substances for personal consumption \\
\hline E165 & assets \\
\hline E225 & climate \\
\hline E210 & physical geography \\
\hline E310 & immediate family \\
\hline E320 & friends \\
\hline E355 & health professionals \\
\hline E340 & personal care providers and personal assistants \\
\hline E360 & health related professionals \\
\hline E325 & $\begin{array}{l}\text { acquaintances, peers colleagues, neighbours, and com- } \\
\text { munity members }\end{array}$ \\
\hline E330 & people in positions of authority \\
\hline E315 & extended family \\
\hline E410 & individual attitudes of immediate family members \\
\hline $\mathrm{E} 420$ & individual attitudes of friends \\
\hline $\mathrm{E} 450$ & individual attitudes of health professionals \\
\hline E455 & individual attitudes of health related professionals \\
\hline E425 & $\begin{array}{l}\text { individual attitudes of acquaintances, peers colleagues, } \\
\text { neighbours, and community members }\end{array}$ \\
\hline E440 & $\begin{array}{l}\text { individual attitudes of personal care providers and } \\
\text { personal assistants }\end{array}$ \\
\hline E460 & societal attitudes \\
\hline $\mathrm{E} 430$ & individual attitudes of people in positions of authority \\
\hline E570 & social security services, systems, and policies \\
\hline E575 & general social support services, systems, and policies \\
\hline E525 & housing services, systems, and policies \\
\hline E540 & transportation services, systems, and policies \\
\hline
\end{tabular}


TABle 3: Continued.

\begin{tabular}{ll}
\hline ICF code & ICF category title \\
\hline E590 & $\begin{array}{l}\text { labour and employment services, systems, and policies } \\
\text { utilities services, systems, and policies } \\
\text { E530 }\end{array}$ \\
E510 & $\begin{array}{l}\text { consumer goods } \\
\text { architecture and construction services, systems, and } \\
\text { policies }\end{array}$ \\
E515 & health services, systems, and policies \\
E580
\end{tabular}

(Adapted from Khan and Pallant [18].)

TABLE 4: Key skills in neurological palliative care and rehabilitation.

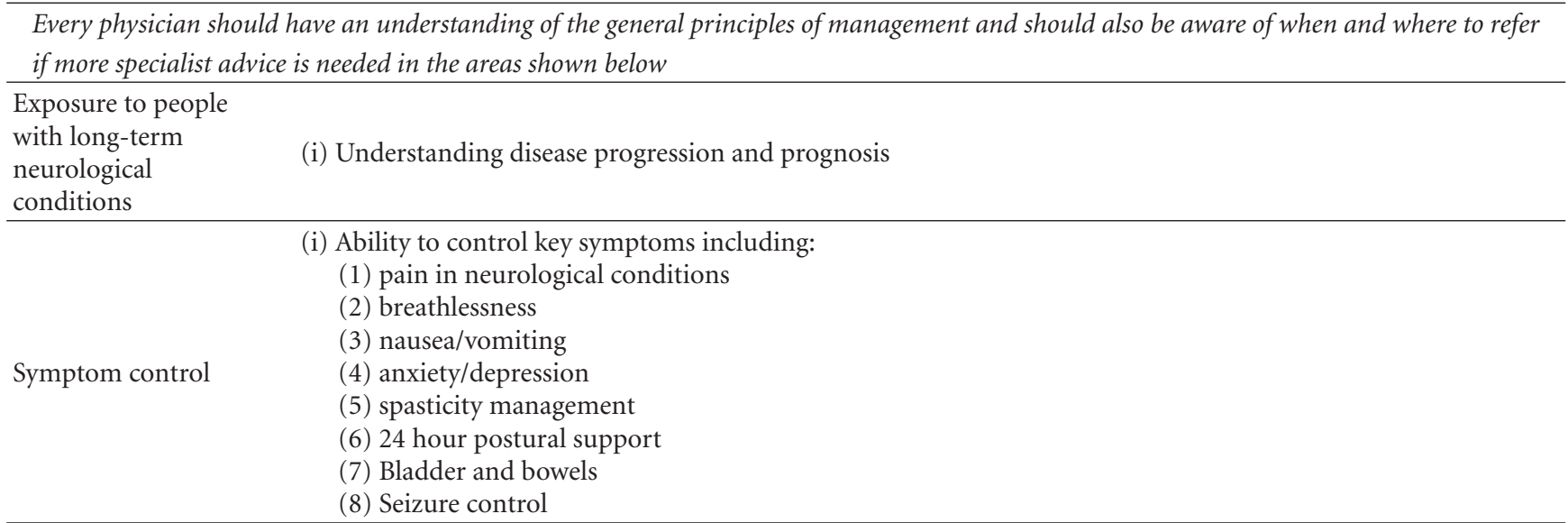

(i) Basic understanding of common communication problems including dysphasia, dysarthria, cognitive speech disorders, and the different approaches to their management.

(ii) Ability to communicate with people who have cognitive/communication impairments

(1) using assistive communication devices

Communication (iii) Communicating with patient and family

(1) breaking bad news

(2) addressing end of life decisions and advance care planning which will include choice over place of care.

(3) Managing expectations.

\begin{tabular}{|c|c|}
\hline Legal issues & $\begin{array}{l}\text { (i) Ability to assess for mental capacity and to assist people to make advance decisions and statements. } \\
\text { (ii) Understanding of the Mental Capacity Act } 2005 \text { and ability to work alongside lasting power of } \\
\text { attorney/court appointed deputy or independent mental capacity advocates. }\end{array}$ \\
\hline \multicolumn{2}{|c|}{ Additional skills for physicians specializing in neurological palliative care and rehabilitation } \\
\hline $\begin{array}{l}\text { Specialist } \\
\text { interventions }\end{array}$ & $\begin{array}{l}\text { (i) Local and intrathecal interventions for spasticity (e.g., injection of botulinum toxin/phenol and use of } \\
\text { baclofen pumps). } \\
\text { (ii) Specialist procedures for pain control. } \\
\text { (iii) Management of confusion/unwanted behaviours-management under sections of the Mental Health Act } \\
1983 \\
\text { (iv) Ventilation }\end{array}$ \\
\hline Specialist equipment & $\begin{array}{l}\text { (i) Wheelchair seating systems } \\
\text { (ii) Environmental control systems } \\
\text { (iii) Specialist communication aids }\end{array}$ \\
\hline $\begin{array}{l}\text { Counselling and } \\
\text { psychological support }\end{array}$ & $\begin{array}{l}\text { (i) Dealing with loss and fear of loss } \\
\text { (ii) Spiritual support } \\
\text { (iii) Bereavement-past and future }\end{array}$ \\
\hline Welfare advice & $\begin{array}{l}\text { (i) Understanding the social care system and benefits } \\
\text { (ii) Vocational support }\end{array}$ \\
\hline $\begin{array}{l}\text { Additional sources of } \\
\text { help and support }\end{array}$ & $\begin{array}{l}\text { (i) Understanding the interaction between health, social services and voluntary support agencies } \\
\text { (ii) Negotiating skills in obtaining services }\end{array}$ \\
\hline
\end{tabular}

(Printed with permission: RCP 2008 [25].) 


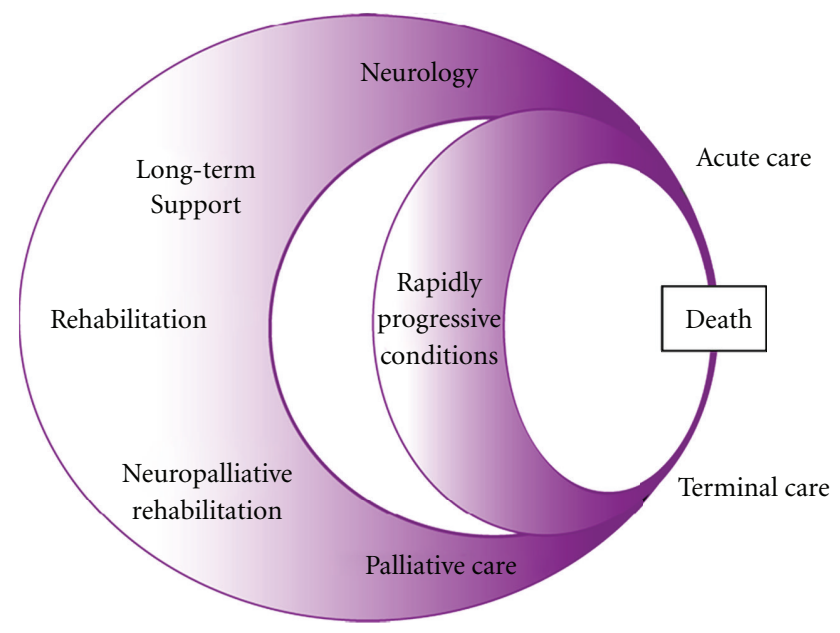

FIGURE 2: Life overlap diagram: interface between neurology, rehabilitation and palliative care in the management of persons with long-term neurological conditions and primary progressive multiple sclerosis. (Printed with permission: Turner-Stokes et al. [41].)

\section{Symptomatic Management and Rehabilitation}

This section outlines the symptomatic and disability management of persons with MS, including PPMS. As PPMS is a progressive disease, regular patient evaluation and reassessment of treatment and management is required. The rehabilitation intervention principles and "neuropalliation" apply to this patient population. The management strategy includes education, therapy input, and medications.

PPMS presents primarily as progressive disease at onset; however, a minority may present with an acute relapse with a wide range of symptoms and signs. The most common patient reported symptoms that have a disabling impact are fatigue, mobility-related issues, and bladder and bowel dysfunction. One study of 101 pwMS showed the "linkage" of patient reported MS related problems and degree of limitation caused using the WHO ICF categories for the components: Body structure, Body Function, Activities and Participation, and Environmental factors [19], Table 5.

\subsection{Disabilities in MS}

5.1.1. Fatigue. Fatigue is one of the most common symptoms in MS reported by up to $95 \%$ of pwMS. It is defined as "subjective" lack of physical or mental energy that is perceived by the individual or caregiver to interfere with usual activities and is present $60 \%$ of the time. In a sample of 656 patients with MS, 22\% reported limitation in level of physical activity, $14 \%$ stated it required them to have more frequent rest breaks and $10 \%$ had to discontinue work due to fatigue [50]. Fatigue impacts on ability to work, social life and on activities of daily living. It is however difficult to predict and is unrelated to age, gender, disability as measured by Kurtzke Expanded Disability Status Scale (EDSS) [51] score or Neuro imaging status. Factors believed to contribute to fatigue in MS are summarized in Box 5.

There are a number of measures of MS-related fatigue [48] (see Table 6).

Treatment of fatigue should be individualized based on the medical and functional status of each patient. The quality and quantity of fatigue, and its impact on function is obtained on history. Other non-MS causes should be excluded (anaemia and hypothyroidism) and contributing factors identified. Medications and side effects should be reviewed. Nonpharmacologic approaches include education for patient and family (avoid heat, use airconditioners, and cooling gel vests), address lifestyle factors, for example, diet and exercise, avoid physical activity at mid afternoon (as a small rise in core body temperature worsens fatigue and MS lassitude or lack of energy). Fatigue management and pacing (regular rest breaks between activities, i.e., pacing activities throughout the day), energy conservation, and work simplification strategies to decrease energy consumption and increase economy of effort (use of assistive devices, adaptive equipment such as long handled aids/grab rails, gait aids such as a walking frame, and ankle foot orthoses to improve gait efficiency) and improve overall fitness by structured exercise programs for aerobic capacity and endurance.

There is limited evidence supporting drug efficacy in MS related fatigue. Modafinil, a "wake promoting" agent that selectively works in the hypothalamic pathways, has been reported to improve fatigue in progressive MS. Amino pyridines (potassium channel blockers) and amantadine (Nmethyl D-aspartate receptor antagonist) have been used, however systematic reviews failed to find evidence for efficacy or safety of their use [52]. Depression may contribute to fatigue in some cases and there is empiric support for use of antidepressants in MS related fatigue. A clinical decision making flowchart for managing fatigue in MS is shown in Figure 3 [48].

5.1.2. Bladder, Bowel, and Sexual Dysfunction. Abnormalities in bladder function are primarily neurogenic and occur in over $80 \%$ of patients. Bladder dysfunction has a detrimental impact on mobility, everyday living activities, and on QoL in pwMS [53]. A recent RCT $(n=74)$ showed effectiveness of multidisciplinary rehabilitation for individualized bladder management program [54]. Approximately two thirds of patients on functional studies demonstrate overactive detrusor function, while the remainder exhibit underactivity. The external urethral sphincter complex may be synergic or dyssynergic with bladder contraction. Detrusor sphincter dyssynergia increases risk of pyelonephritis and renal failure due to combined effects of back pressure and reflux of infected urine into the kidney. Symptoms are unreliable in determining the precise underlying functional abnormality. Risk factors for progressive upper urinary tract dysfunction in MS, which require longer-term followup include: detrusor sphincter dyssynergia, age over 50 years, and male gender [55].

Urodynamic studies are mandatory to evaluate the pattern of neurogenic bladder dysfunction in an individual. On a day-to-day basis, general techniques for managing 
TABle 5: Frequency of limitations reported by persons with MS $(N=101)$ linked with ICF categories for the components: body function, body structure, activity and participation, and environmental factors (those reported by at least one third of MS patients are listed below).

\begin{tabular}{|c|c|c|c|c|c|c|c|}
\hline \multirow[t]{2}{*}{ ICF code } & \multirow[t]{2}{*}{ Chapter title } & \multirow[t]{2}{*}{ ICF code description } & \multirow{2}{*}{$\begin{array}{l}\text { Total number of } \\
\text { participants linked } \\
\text { responses. } n, \%\end{array}$} & \multicolumn{4}{|c|}{ Number of participant and stage of disease } \\
\hline & & & & $\mathrm{RR}$ & SP & PP & rr-SP \\
\hline & & Body function & & & & & \\
\hline b130 & $\begin{array}{l}\text { Global mental } \\
\text { functions }\end{array}$ & Energy and drive functions & $98,97.03$ & 51 & 26 & 14 & 7 \\
\hline b134 & & Sleep & $84,83.17$ & 47 & 21 & 11 & 5 \\
\hline b140 & $\begin{array}{l}\text { Specific mental } \\
\text { functions }\end{array}$ & Attention & $66,65.35$ & 37 & 17 & 9 & 3 \\
\hline b144 & & Memory & $62,61.39$ & 37 & 16 & 4 & 5 \\
\hline b152 & & Emotional functions & $97,96.04$ & 50 & 26 & 14 & 7 \\
\hline b210 & $\begin{array}{l}\text { Seeing and related } \\
\text { functions }\end{array}$ & Seeing & $47,46.53$ & 24 & 16 & 4 & 3 \\
\hline b235 & Hearing vestibular & $\begin{array}{l}\text { Vestibular (incl. balance } \\
\text { functions) }\end{array}$ & $71,70.30$ & 34 & 19 & 13 & 5 \\
\hline b265 & Sensory functions & Touch & $34,33.66$ & 15 & 10 & 7 & 2 \\
\hline b280 & Pain & Sensation of pain & $76,75.25$ & 39 & 19 & 12 & 6 \\
\hline B455 & $\begin{array}{l}\text { CVS and respiratory } \\
\text { functions }\end{array}$ & $\begin{array}{l}\text { Exercise tolerance } \\
\text { functions* }\end{array}$ & $97,96.04$ & 50 & 27 & 13 & 7 \\
\hline b525 & Digestive system & Defecation & $89,88.12$ & 49 & 21 & 14 & 5 \\
\hline b620 & Urinary functions & Urination functions & $94,93.07$ & 50 & 24 & 13 & 7 \\
\hline b640 & $\begin{array}{l}\text { Genital and } \\
\text { reproductive }\end{array}$ & Sexual functions & $57,56.44$ & 32 & 15 & 7 & 3 \\
\hline b730 & Muscle functions & Muscle power & $96,95.05$ & 50 & 27 & 13 & 6 \\
\hline b735 & & Muscle tone & $94,93.07$ & 50 & 26 & 13 & 5 \\
\hline b740 & & $\begin{array}{l}\text { Muscle endurance } \\
\text { function* }\end{array}$ & $93,92.08$ & 49 & 25 & 12 & 7 \\
\hline b760 & Movement functions & $\begin{array}{l}\text { Control of voluntary } \\
\text { movement functions* }\end{array}$ & $66,65.35$ & 37 & 18 & 8 & 3 \\
\hline \multirow[t]{2}{*}{ b770 } & & Gait pattern functions* & $99,98.02$ & 51 & 27 & 13 & 8 \\
\hline & & Body Structure & & & & & \\
\hline s110 & Nervous system & Brain & $100,99.01$ & 50 & 28 & 14 & 8 \\
\hline s610 & Genitourinary system & Urinary system & $93,92.08$ & 49 & 25 & 12 & 7 \\
\hline s730 & $\begin{array}{l}\text { Structures related to } \\
\text { movement }\end{array}$ & $\begin{array}{l}\text { Upper extremity (arm, } \\
\text { hand) }\end{array}$ & $44,43.56$ & 25 & 10 & 7 & 2 \\
\hline s750 & & Lower extremity (leg, foot) & $97,96.04$ & 49 & 27 & 14 & 7 \\
\hline \multirow[t]{2}{*}{ s760 } & & Trunk & $85,84.16$ & 44 & 23 & 12 & 6 \\
\hline & & Activities and participation & & & & & \\
\hline $\mathrm{d} 160$ & Applying knowledge & Focussing attention & $70,69.31$ & 39 & 16 & 9 & 6 \\
\hline d175 & & Solving problems & $34,33.66$ & 22 & 8 & 2 & 2 \\
\hline d177 & & Making decisions & $59,58.42$ & 35 & 16 & 5 & 3 \\
\hline $\mathrm{d} 220$ & $\begin{array}{l}\text { General tasks and } \\
\text { demands }\end{array}$ & Undertaking multiple tasks & $88,87.13$ & 47 & 24 & 12 & 5 \\
\hline $\mathrm{d} 230$ & & Carrying out daily routine & $80,79.21$ & 48 & 17 & 10 & 5 \\
\hline $\mathrm{d} 240$ & & $\begin{array}{l}\text { Handling stress and other } \\
\text { psychological demands }\end{array}$ & $101,100.00$ & 51 & 28 & 14 & 8 \\
\hline $\mathrm{d} 430$ & Mobility & $\begin{array}{l}\text { Lifting and carrying } \\
\text { objects }\end{array}$ & $53,52.48$ & 30 & 12 & 8 & 3 \\
\hline $\mathrm{d} 440$ & & $\begin{array}{l}\text { Fine hand use (picking up, } \\
\text { grasping) }\end{array}$ & $51,50.50$ & 26 & 13 & 9 & 3 \\
\hline
\end{tabular}


Table 5: Continued.

\begin{tabular}{|c|c|c|c|c|c|c|c|}
\hline \multirow[t]{2}{*}{ ICF code } & \multirow[t]{2}{*}{ Chapter title } & \multirow[t]{2}{*}{ ICF code description } & \multirow{2}{*}{$\begin{array}{l}\text { Total number of } \\
\text { participants linked } \\
\text { responses. } n, \%\end{array}$} & \multicolumn{4}{|c|}{ Number of participant and stage of disease } \\
\hline & & & & $\mathrm{RR}$ & SP & PP & rr-SP \\
\hline d445 & & Hand and arm use & $37,36.63$ & 21 & 9 & 4 & 3 \\
\hline $\mathrm{d} 450$ & & Walking & $101,100.00$ & 51 & 28 & 14 & 8 \\
\hline $\mathrm{d} 455$ & & Moving around* & $99,98.02$ & 51 & 27 & 14 & 7 \\
\hline $\mathrm{d} 465$ & & $\begin{array}{l}\text { Moving around and } \\
\text { using equipment } \\
\text { (wheelchair, skates, etc.) }\end{array}$ & $98,97.03$ & 50 & 27 & 14 & 7 \\
\hline $\mathrm{d} 470$ & & $\begin{array}{l}\text { Using transportation } \\
\text { (car, bus, train, plane, } \\
\text { etc.) }\end{array}$ & $100,99.01$ & 51 & 27 & 14 & 8 \\
\hline $\mathrm{d} 475$ & & $\begin{array}{l}\text { Driving (riding bicycle } \\
\text { and motorbike, driving } \\
\text { car etc.) }\end{array}$ & $99,98.02$ & 51 & 27 & 14 & 7 \\
\hline $\mathrm{d} 510$ & Self care & $\begin{array}{l}\text { Washing oneself } \\
\text { (bathing, drying, } \\
\text { washing hands, etc.) }\end{array}$ & $41,40.59$ & 26 & 9 & 4 & 2 \\
\hline d520 & & $\begin{array}{l}\text { Caring for body parts } \\
\text { (brushing teeth, shaving, } \\
\text { grooming, etc.) }\end{array}$ & $40,39.60$ & 24 & 8 & 5 & 3 \\
\hline d570 & & $\begin{array}{l}\text { Looking after one's } \\
\text { health }\end{array}$ & $88,87.13$ & 47 & 23 & 14 & 4 \\
\hline d620 & Domestic life & $\begin{array}{l}\text { Acquisition of goods and } \\
\text { services (shopping, etc.) }\end{array}$ & $92,91.09$ & 50 & 24 & 12 & 6 \\
\hline $\mathrm{d} 630$ & & $\begin{array}{l}\text { Preparation of meals } \\
\text { (cooking etc.) }\end{array}$ & $89,88.12$ & 48 & 24 & 12 & 5 \\
\hline $\mathrm{d} 640$ & & $\begin{array}{l}\text { Doing housework } \\
\text { (cleaning washing, } \\
\text { laundry, and ironing) }\end{array}$ & $94,93.07$ & 51 & 23 & 14 & 6 \\
\hline d650 & & $\begin{array}{l}\text { Caring for household } \\
\text { objects* }\end{array}$ & $84,83.17$ & 46 & 22 & 12 & 4 \\
\hline d660 & & Assisting others & $87,86.14$ & 48 & 22 & 13 & 4 \\
\hline $\mathrm{d} 750$ & $\begin{array}{l}\text { Interpersonal } \\
\text { relationships }\end{array}$ & $\begin{array}{l}\text { Informal social } \\
\text { relationships }\end{array}$ & $35,34.65$ & 19 & 12 & 2 & 2 \\
\hline $\mathrm{d} 760$ & & Family relationships & $73,72.28$ & 42 & 16 & 11 & 4 \\
\hline $\mathrm{d} 770$ & & Intimate relationships & $61,60.40$ & 35 & 15 & 7 & 4 \\
\hline $\mathrm{d} 845$ & Work & $\begin{array}{l}\text { Acquiring keeping and } \\
\text { terminating a job* }\end{array}$ & $73,72.28$ & 39 & 19 & 11 & 4 \\
\hline $\mathrm{d} 850$ & & $\begin{array}{l}\text { Remunerative } \\
\text { employment }\end{array}$ & $90,89.11$ & 45 & 24 & 13 & 8 \\
\hline $\mathrm{d} 870$ & Economic life & $\begin{array}{l}\text { Economic } \\
\text { self-sufficiency }\end{array}$ & $84,83.17$ & 44 & 22 & 13 & 5 \\
\hline d910 & Community life & Community Life & $79,78.22$ & 40 & 21 & 13 & 5 \\
\hline \multirow[t]{2}{*}{ d920 } & & Recreation and leisure & $97,96.04$ & 50 & 26 & 14 & 7 \\
\hline & & Environmental Factors & & & & & \\
\hline e110 & Products and technology & $\begin{array}{l}\text { For personal } \\
\text { consumption (food, } \\
\text { medicines) }\end{array}$ & $101,100.00$ & 51 & 28 & 14 & 8 \\
\hline e120 & & $\begin{array}{l}\text { For personal indoor and } \\
\text { outdoor mobility and } \\
\text { transportation }\end{array}$ & $91,90.10$ & 47 & 25 & 12 & 7 \\
\hline e150 & & $\begin{array}{l}\text { Design, construction } \\
\text { and building products } \\
\text { and technology of } \\
\text { buildings for public use }\end{array}$ & $70,69.31$ & 39 & 18 & 9 & 4 \\
\hline
\end{tabular}


Table 5: Continued.

\begin{tabular}{|c|c|c|c|c|c|c|c|}
\hline \multirow[t]{2}{*}{ ICF code } & \multirow[t]{2}{*}{ Chapter title } & \multirow[t]{2}{*}{ ICF code description } & \multirow{2}{*}{$\begin{array}{l}\text { Total number of } \\
\text { participants linked } \\
\text { responses. } n, \%\end{array}$} & \multicolumn{4}{|c|}{ Number of participant and stage of disease } \\
\hline & & & & $\mathrm{RR}$ & SP & $\mathrm{PP}$ & rr-SP \\
\hline e210 & Natural environment & Physical geography* & $39,38.61$ & 21 & 11 & 5 & 2 \\
\hline e225 & & Climate & $99,98.02$ & 50 & 28 & 14 & 7 \\
\hline e310 & $\begin{array}{l}\text { Support and } \\
\text { relationships }\end{array}$ & Immediate family & $45,44.55$ & 27 & 9 & 7 & 2 \\
\hline e315 & & Extended family* & $42,41.58$ & 26 & 9 & 3 & 4 \\
\hline e460 & Attitudes & Societal attitudes & $31,30.69$ & 13 & 9 & 5 & 4 \\
\hline e540 & $\begin{array}{l}\text { Services, systems, and } \\
\text { policies }\end{array}$ & $\begin{array}{l}\text { Transportation services, } \\
\text { systems and policies }\end{array}$ & $68,67.33$ & 38 & 17 & 8 & 5 \\
\hline e580 & & $\begin{array}{l}\text { Health services, systems } \\
\text { and policies }\end{array}$ & $79,78.22$ & 45 & 18 & 11 & 5 \\
\hline
\end{tabular}

(Adapted from Khan and Pallant [19].)

TABLE 6: Measures of multiple sclerosis related fatigue.

\begin{tabular}{|c|c|c|c|c|c|}
\hline Name of scale & Author, year [ref.] & Population & $\begin{array}{l}\text { Specified fatigue } \\
\text { subscales }\end{array}$ & No. of items & Scoring \\
\hline $\begin{array}{l}\text { Modified fatigue } \\
\text { impact scale }\end{array}$ & $\begin{array}{c}\text { Paralysed Veterans of } \\
\text { America } 1998 \text { [42] }\end{array}$ & MS & $\begin{array}{l}\text { Physical, cognitive } \\
\text { and psychosocial }\end{array}$ & 21 & Likert scale \\
\hline $\begin{array}{l}\text { Rochester fatigue } \\
\text { diary }\end{array}$ & $\begin{array}{c}\text { Schwid et al., } 2002 \\
\text { [43] }\end{array}$ & MS & $\begin{array}{l}\text { Lassitude (reduced } \\
\text { energy) }\end{array}$ & $\begin{array}{l}12(1 \text { item, } 12 \text { times } \\
\text { over } 24 \mathrm{~h})\end{array}$ & Visual analogue scale \\
\hline $\begin{array}{l}\text { Fatigue descriptive } \\
\text { scale }\end{array}$ & Iriarte et al., 1999 [44] & MS & $\begin{array}{l}\text { Spontaneous mention } \\
\text { of fatigue, antecedent } \\
\text { conditions, frequency, } \\
\text { and impact on life }\end{array}$ & 5 & $0-3$ \\
\hline Fatigue impact scale & Fisk et al., 1994 [45] & MS & $\begin{array}{l}\text { Physical, cognitive, } \\
\text { and psychosocial }\end{array}$ & 21 & $0-4$ \\
\hline $\begin{array}{l}\text { Fatigue assessment } \\
\text { instrument }\end{array}$ & $\begin{array}{c}\text { Schwartz et al., } 1993 \\
{[46]}\end{array}$ & $\begin{array}{c}\text { Lynne, Chronic } \\
\text { fatigue syndrome, } \\
\text { lupus, Ms, dysthymia, } \\
\text { healthy }\end{array}$ & $\begin{array}{l}\text { Fatigue severity, } \\
\text { situation specificity, } \\
\text { consequences of } \\
\text { fatigue, and responds } \\
\text { to rest/sleep }\end{array}$ & 29 & $1-7$ \\
\hline $\begin{array}{l}\text { Single item visual } \\
\text { analogue scale of } \\
\text { fatigue }\end{array}$ & $\begin{array}{c}\text { Krupp et al., } 1989 \\
{[47]}\end{array}$ & MS, lupus, healthy & None & 1 & Visual analogue scale \\
\hline Fatigue severity scale & $\begin{array}{c}\text { Krupp et al., } 1989 \\
{[47]}\end{array}$ & MS, lupus, healthy & None & 9 & Likert scale \\
\hline
\end{tabular}

(Adapted from: MacAllister and Krupp [48].)

Primary factors

(i) Immune dysregulation — changes in neuroendocrine function.

(ii) Central nervous system mechanisms_-neuronal dysfunction due to immune injury, demyelination and inflammation, impaired innervation, and activation of muscle groups leading to compensatory increase in central motor drive exertion and more energy depletion.

(iii) Endocrine factors_abnormalities in hypothalamic/pituitary/adrenal axis.

(iv) Neurotransmitter dysregulation-dopaminergic, histaminergic, and serotonergic pathways may contribute to fatigue.

Secondary factors.

(i) Physical deconditioning from failure to get adequate exercise.

(ii) Sleep dysfunction-may also be due to nocturnal spasms, pain, incontinence, and depression.

(iii) Pain-sensory disturbances, neuralgia, dysesthesia, and spasms.

(iv) Depression - in closely related to poor sleep, pain, and fatigue.

(v) Medications_can worsen fatigue (antispasticity agents, e.g., Baclofen).

Box 5: Primary and secondary factors in multiple sclerosis fatigue. (Adapted from: MacAllister and Krupp [48]). 


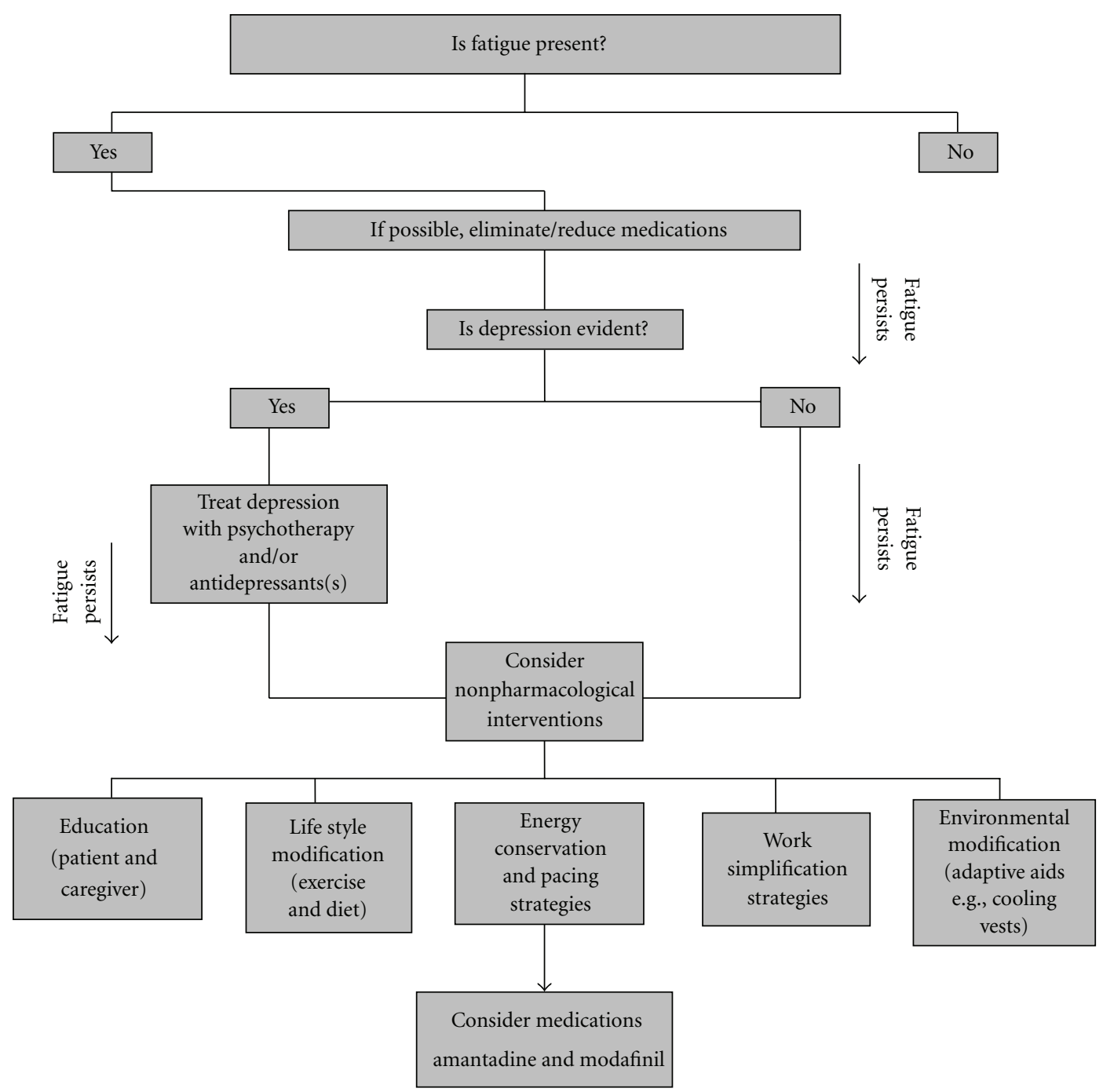

FIGURE 3: Clinical decision making flow chart for treating fatigue in MS. (Adapted from: MacAllister and Krupp [48].)

bladder care include scheduled fluid intake, timed voiding pattern, establishment of emptying techniques every three hours (tapping over suprapubic region, Credes maneuver), use of pads and undergarments, and use of bedside commode or urinal. Other simpler techniques such as voided volume charts will provide evidence of small frequent urine volumes suggesting detrusor hyperactivity. Postmicturition ultrasound should be performed regularly and if residual volumes exceed $100 \mathrm{~mL}$, a regimen of intermittent clean selfcatheterisation should be introduced. If this is not possible due to upper limb dysfunction or adductor spasm, long-term catheterisation should be considered.

Detrusor overactivity can be treated with anticholinergic medications (oxybutynin, imipramine, solifenacin, and tolterodine) and in severe cases with intravesical oxybutynin or botulinum toxin. Additional techniques for managing bladder include scheduled fluid intake, prompted voiding, avoidance of alcohol and caffeine, pelvic floor exercises and other behaviour modifications. For detrusor sphincter dysynergia regular attempts to void (light tapping), trial of antispasticity agents (baclofen), alpha adrenergic blocking agents (prazosin and clonidine), and anticholinergic medications (oxybutynin) with intermittent catheterization can be trialed. Detrusor underactivity causes incomplete bladder emptying and can be managed with intermittent catheterization; if these are unsuccessful, an indwelling catheter may be needed. Suprapubic catheterisation is preferable than urethral catheterization, as they have fewer complications including urinary infections, are easier to change, and permit normal sexual functioning. Figure 4 provides a flow chart for managing urinary incontinence in patients with long-term neurological conditions including PPMS [39].

Symptomatic lower urinary tract infections should be treated on the basis of a positive urine culture. Acidifying agents such as cranberry can reduce risk of recurrent urinary infections in neurogenic bladders. Symptomatic management of lower urinary tract symptoms includes the antidiuretic hormone desmopressin (DDAVP) nasal spray for nocturia and oral cannabinoids. Bladder retraining and pelvic floor exercises may be useful if patients are 


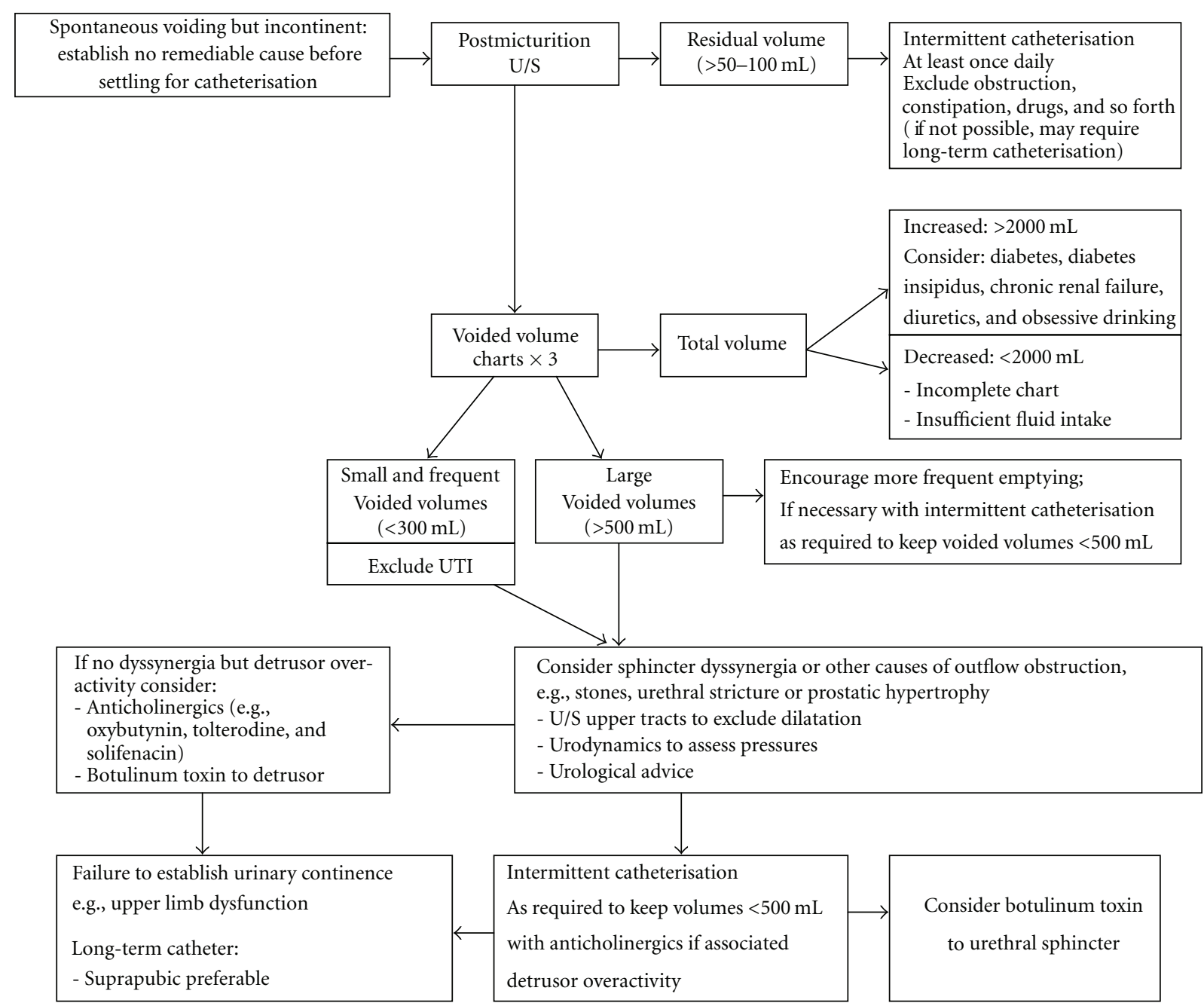

FIGURE 4: Managing urinary incontinence in patients with long term neurological conditions including primary progressive MS. (Printed with permission: RCP 2008 [25].)

appropriately educated in conjunction with a physiotherapist. Patients should be provided with tips to prevent recurrent urinary infections such as awareness of signs of infection (cloudy urine or pain and odor), adequate fluid intake (8 glasses per day), increase urine acidity (vitamin C) or cranberry capsule daily, try to achieving complete bladder emptying, wiping front to back after going to the bathroom, and regular change of indwelling catheters (4-6 weekly).

Bowel dysfunction has been reported in $50 \%$ of pwMS, with constipation, and faecal incontinence. These result from autonomic dysfunction and abnormal rectal function. Absent rectal sensations increase risk of faecal incontinence, which can reflect decreased rectal filling sensation, poor sphincter and pelvic floor contraction and decreased rectal compliance. A recent study identified female sex, higher disability, and urinary dysfunction as independent predictors of developing anorectal dysfunction [56]. Bowel programs need to be effective (i.e., complete within 60 minutes from beginning of program to bowel evacuation). Patient education includes review of diet and bowel habits. The optimization of consistency of bowel contents is ensured by adequate oral intake, a diet high in fibre and laxatives (bowel softeners such as coloxyl) if necessary. Next is the facilitation of the movement of the bowel contents, a combination of osmotic (e.g., lactulose) and stimulants (e.g., senna) is effective and is the mainstay medical treatment. The iso-osmotic laxative polyethylene glycol (Movicol) has been shown to be effective in chronic constipation and is used in resistant cases. Frequent use of enemas should be avoided. The timing of a bowel program ideally should be postprandial when the gut is most active. Rectal stretching (suppository) can facilitate the defecation reflex and assist bowel evacuation. A flow chart outlining bowel management in pwMS is shown in Figure 5.

Sexual dysfunction in MS has been widely reported especially in patients with urinary symptoms [57]. Causes of sexual dysfunction may be primary (lack of lubrication, diminished genital sensations, erectile dysfunction), secondary (spasticity, pain, catheter care) or tertiary (marital difficulty, fear, and lack of confidence and self-worth). Men 


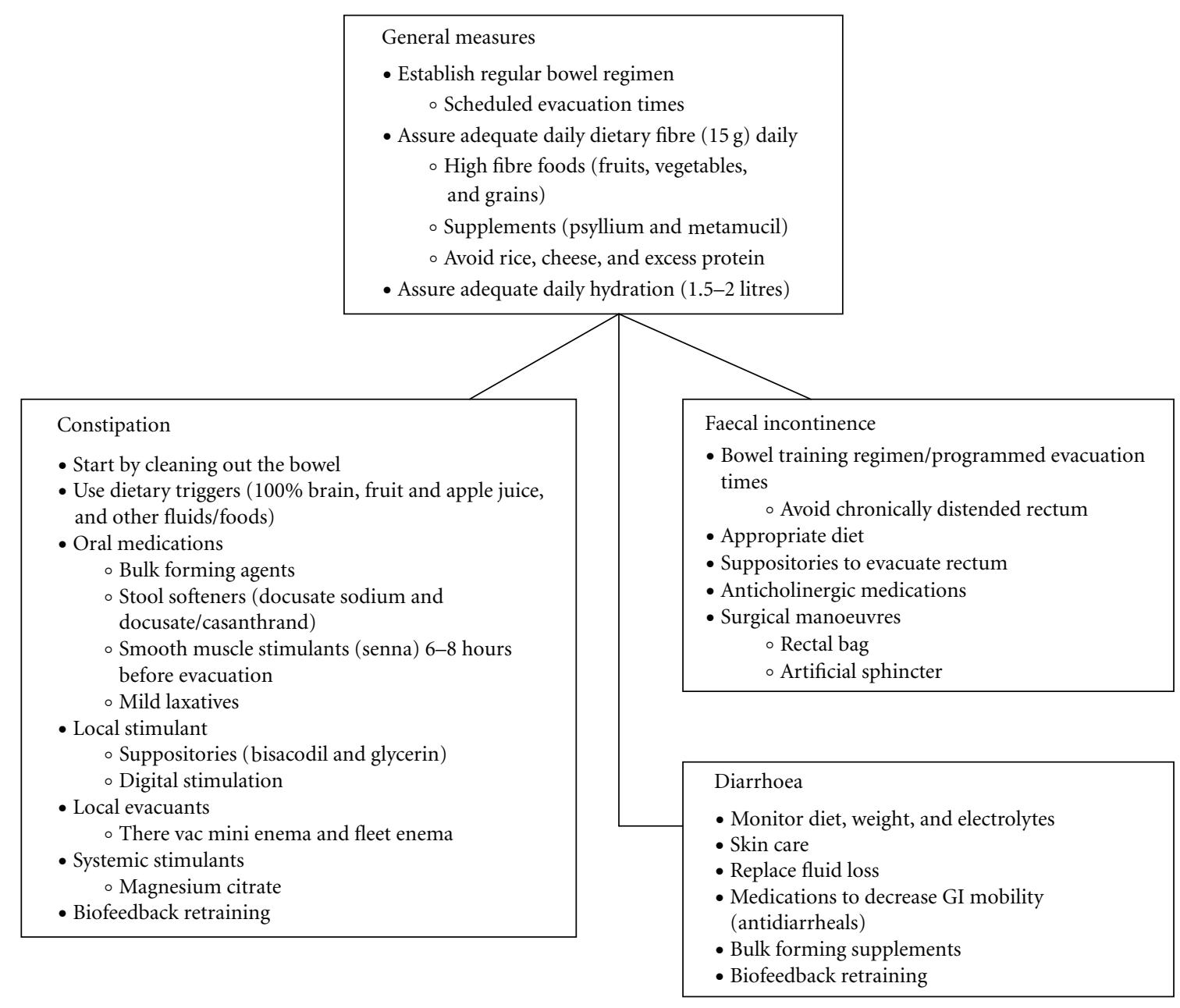

FIgUre 5: Management of bowel problems in MS. (Adapted from: Miller et al. [49].)

commonly report diminished libido, erectile and ejaculatory dysfunction. Women report diminished genital sensation, lubrication, and difficulty achieving orgasm. Rehabilitation includes education about intimacy and sexuality, management of fatigue, positioning, and mechanics, information about aids (tumescence devices), specific suggestions and techniques, and referral for sexual counselling. The use of oral phosphodiesterase inhibitors (e.g., sildenafil) have been successful in treating erectile dysfunction in men; their role in women has not been established. In addition to intracorporeal pharmacotherapy, papaverine has now been replaced by prostaglandin E1 by intracavernosal injection or urethral application.

5.1.3. Mobility Related Symptoms. Mobility can be affected in MS from a combination of motor (weakness and spasticity), sensory (proprioception loss, ataxia), fatigue, and visual impairments.

Spasticity. Spasticity, a velocity-dependent increase in muscle tone, is a common complication of MS. Muscle shortening and restricted movements lead to decreased tissue compliance and biomechanical difficulties (contractures) which can limit a person's activity (mobility, ability to transfer, perform self-care tasks, and pain) and participation (unable to drive or work). Management of spasticity in pwMS is complicated due to lesions in the brain and spinal cord, numerous other secondary MS-related impairments, and their associated polypharmacy. There are limited studies which do not suggest improved outcomes of one strategy for managing spasticity compared with another. Two useful measure of spasticity include the spasm frequency scale [58] and the modified ashworth scale [59]. The spasm frequency scale is obtained from history, and is a $0-4$ non interval scale: 0: no spasms, 4: 10 spontaneous spasms per hour. The modified ashworth scale is obtained after clinical examination and is also a non interval scale of 0-4 (although it includes a value for $1+$ ), with 0 : "no increase in tone", 4 : "affected part is rigid". More recently, a systematic review found the Tardieu scale to be a more sensitive measure for spasticity; however, further validity validation of this scale for various muscle groups is required [60].

The treatment goals change with progression of disease. Early in the course of the disease, spasticity can interfere with functional activities and also cause gait inefficiency, which in 
turn increases fatigue. On the other hand, as muscles weaken, some patients rely on their spasticity to keep them on their feet. Carefully targeted intervention for those elements of spasticity that are unwanted can assist with energy conservation and so keep pwMS mobile and independent for longer. Later on, the focus of treatment is more on improving ease of maintaining hygiene, prevention of contractures and pain reduction. Management involves patient education, therapy intervention, and medication [28]. The aims of therapy are awareness of symptoms related to spasticity and awareness of factors that can worsen spasticity for example, noxious stimuli, sudden movements, anxiety; correct positioning and alignment, and a stretching program. The mainstay of treatment is maintaining muscle length, so the importance of positioning and physical management (such as a regular standing regimen) cannot be over-estimated. Drugs are an adjunct to these interventions and may be given orally or by intramuscular, intraneural, or intrathecal injection.

Oral antispasticity agents are first-line therapy for generalised spasticity [28]. The most commonly prescribed oral agents include baclofen, tizanidine, clonazepam, and dantrolene. Baclofen (gamma amino butyric acid agonist) remains the agent of first choice though its use is restricted by side effects including weakness, fatigue, and cognitive impairment. Tizanidine (central acting $\alpha 2$ adrenergic agonist) can be used in conjunction with baclofen or in isolation in patients who cannot tolerate or have no response to baclofen. Clonazepam (benzodiazepine) is particularly effective at treating nocturnal spasms. Its side effect profile includes sedation and effects on cognition. Dantrolene acts at the level of the muscle and can be used with any of the above agents for severe generalized spasticity. Its use is limited by its side-effect profile and poor tolerability. 4Aminopyridine (Dalfampridine and Fampridine) (voltagegated potassium channel blocker) has been shown to provide improvement in lower limb function, but toxicity with seizures and encephalopathy can occur at therapeutic doses $[61,62]$. Other pharmacological agents such as Memantine did not show any benefit in treatment of spasticity [63]. Cannabis extracts are reported to have positive effect on spasticity and can be prescribed orally or via nasal spray [28]. Cannabinoids act on CB1 receptors in the CNS to inhibit cyclic AMP and voltage-dependent calcium channels, causing antispastic effect.

Intrathecal Baclofen (ITB) is effective for severe generalised spasticity, particularly in the lower limbs. It requires lower doses and has improved tolerability due to less sedative and cognitive side effects. However, ITB withdrawal syndrome (incorrect dosage and pump failure) can be life threatening, and therefore, this treatment should only be managed in specialist units [64]. For focal spasticity, botulinum toxin injected into the affected muscle(s) can be effective [65]. Other localized spasticity (adductor muscles) can be treated with phenol neurolysis. Surgical options (tendon release surgery) are reserved for severe spasticity, causing pain, interfering with care, and/or limiting activities of daily living.
Ataxia. Cerebellar problems such as tremor, ataxia, and incoordination are common in pwMS. The action (posturalintention) tremor reflects brainstem-cerebellar circuitary lesions and can be disabling and is often difficult to treat. Symptomatic treatment for tremor includes identification of type of tremor, trigger factors and part of body involved. Use of assistive devices (braces and support) and evaluation for therapy may be helpful. Limited benefit from drug therapy using Ondansetron (for cerebellar tremor), propanolol, and combined therapy with lamotrigine and gabapentin have been reported. Surgical ablative and stimulation techniques (ventral intermediate thalamic nucleus) are currently being trialed.

Truncal ataxia can occur in up to $70 \%$ of pwMS, often accompanied by tremor. It has a significant effect on motor coordination (similar to weakness) and interferes with balance and mobility, increasing predisposition to falls and injury. Patient education and safety in daily living tasks is emphasized as rehabilitation strategies, which include improvement in posture and alignment, proximal stabilization (pectoral and pelvic girdle musculature), coordination exercises, and assistive devices such as the use of distal weights around the wrists to dampen tremor and the use of walking frames or elbow crutches enhance gait stability. Falls prevention strategies and environmental modification (installation of grab rails, nonskid floor mats) can be helpful. In one small RCT $(n=23)$ [66], pwMS were randomized to specific physiotherapy strategies such as (a) facilitation therapy (individualized, passive and active manual assistance, postural control, and component practice as in Bobath technique) and (b) task oriented therapy (nonindividualized, hands off acceptance of compensatory strategies and functional tasks such as stair climbing and treadmill walking). Although patients in both groups showed improvement in gait scores, balance tests and global mobility indices, those in the facilitation group had nonsignificant trends towards greater benefit in all categories. Medications for ataxia are similar to those used for treating tremors (isoniazid, clonazepam, propanolol, gabapentin, and Ondansetron). A recent systematic review found no evidence that medication or neurorehabilitation strategies provide sustained improvement in ataxia in pwMS [67]. Surgical interventions such as thalamotomy or thalamic stimulation in MS have produced limited success.

5.1.4. Pain and Paroxysmal Symptoms. Pain can be acute or chronic. The underlying mechanisms of pain in MS are unclear and have been linked with the differentiation and disinhibition of central and pain pathways [68, 69] with CNS lesions causing hyperexcitability and with increased neuronal activity at the site of the lesion in the spinal cord [70]. Acute pain may be associated with active inflammatory process. Chronic pain may be due to the MS process itself or from complications that arise from it such as trigeminal neuralgia, spasms/spasticity, and musculoskeletal posture and gait-related problems [71].

In one recent Australian series $(n=94) 60 \%$ of patients reported chronic pain, of these $61 \%$ had dysesthetic pain and $70 \%$ had episodic increases in pain [72]. Chronic pain in 
MS impacts on activities of daily living [71] and interferes with ability to work [73]. A recently published study ( $n=$ 62) performed cluster analysis to classify patients into three cognitive behavioral groups (adaptive copers, dysfunctional and interpersonally distressed) and suggested possible cut points to aid clinicians in classifying patients into clusters for individualized treatment [74]. The severity of depression is reported to be higher in persons with MS with chronic pain than those without pain. There is also increased interference with daily activities, more severe symptoms of depression and negative effect on relationships with partners and family [71]. Treatment of chronic pain has been discussed elsewhere [75]. A multidisciplinary team approach may be needed and referral to pain clinic may be helpful.

A systematic approach initially using monotherapy to maximum doses before polytherapy is imperative Amitriptyline is effective for chronic dysesthetic pain. Carbamazepine is the drug of choice for trigeminal neuralgia if not tolerated then alternatives include gabapentin, lamotrigine, and phenytoin [76]. Transcutaneous electrical nerve stimulation to lower back of pwMS appears promising [77]. Surgical options are percutaneous procedures and rarely microvascular surgery [78]. Carbamazepine and gabapentin are agents of choice for other paroxysmal symptoms (tonic spasms, ataxia, or sensory symptoms like Lhermitte's). Cannabisbased preparations are effective for pain in pwMS [79] but are reserved for cases where standard therapies have failed or are not tolerated. There is no evidence to support routine use of intrathecal morphine for pain management in the MS population. Pregabalin, an isomer of GABA with selectively binds to the alfa2-delta protein of the voltagegated calcium channels, has been shown to be efficacious in the management of peripheral neuropathic pain of various causes including MS $[80,81]$.

5.1.5. Cognitive Deficits. Current estimates of prevalence of neuropsychological problems in MS are approximately 50\% $[82,83]$. The neurocognitive and behavioural deficits in MS, and suggested treatments are discussed in a recent review [84]. Cognitive problems result from affected pathways in the cerebral white matter (limbic system, the midbrain, and brainstem), which transmit to, and communicate with, higher-level cortical regions throughout the brain. These deficits can be a major impediment to rehabilitation and include: inability to store and to retrieve information, decreased memory, attention and speed of processing, and limitations in emotion, personality, and behaviour [84-86].

Many guidelines exist for neuropsychological research in MS [84]. Neuropsychological interventions are designed to enhance a person's ability to function in all areas of family and community life, which are meaningful for pwMS. A neuropsychological assessment can be helpful to delineate problems and suggest compensatory techniques. These include functionally oriented therapies based on specific deficits: compensatory strategies (using intact skills or external aids to improve function), substitution (learnt use of intact cognitive abilities to circumvent a problem), or scheduling (templates and structured programs) may assist with everyday living tasks.
A systematic review reported that cognitive behaviour therapies (CBT) were beneficial for pwMS in terms of coping with, and adjustment to MS [33]. Other specific cognitive rehabilitation protocols are being evaluated [87]. Although the evidence for individual interventions is limited, computer-based retraining program was shown to improve deficits related to attention [88]. Medications such as amantadine, glatiramer acetate, memantine, and donepezil failed to improve cognitive function in MS [89-92]; others such as methylphenidate have not yet been studied in pwMS.

5.1.6. Visual and Brainstem Symptoms. Visual disturbances were reported by $58 \%$ of pwMS in one large cohort [93]. Referral to "low vision clinic" may be required for decreased visual acuity (optic neuritis). The visual dysfunction may also result from involuntary eye movement disorders (nystagmus and opsoclonus) [28]. Patient education, use of adaptive visual aids (prisms and magnifying lens), and occasionally medications such as baclofen, isoniazid, and gabapentin may be helpful for involuntary eye movements [94]. Referral to occupational therapy and low vision clinics can be helpful for neuromobility services such as practicing outdoor mobility to improve safe community access.

Vestibular involvement in MS is frequent and causes vertigo and often associated with other signs of brainstem dysfunction. Specific vestibular physiotherapy exercises (such as Cawthorne-Cooksey protocol) may be helpful. Effective speech therapy for dysarthria for MS includes control of speech rate, voice emphasis and power, and reduction in phrase length [95-97]. Dysphagia occurs in about 34\%-43\% of pwMS $[98,99]$. Fatigue, tremors, weakness, and incoordination exacerbate dysphagia and dysarthria. Spasticity is worsened by malnutrition. For the most severely affected pwMS, maintenance of nutritional balance may require placement of a percutaneous peg for feeding. This requires specialized nutritional and speech pathology services. Videofluoroscopy and clinical assessment is recommended for more disabled persons [100]. Speech therapy can provide compensatory strategies to avoid aspiration, correct posture (sitting up when eating), alter food consistency, and provide education to prevent complications (pneumonia) [99].

5.1.7. Psychiatric and Psychological Dysfunction. The prevalence of major depressive disorder in pwMS is reportedly between $27 \%-54 \%$, and nearly double the prevalence in persons without MS over 12 months (15.7\% versus 7.4\%) [101]. There was also an age effect, with a prevalence of $25 \%$ in adults between 18 and 45 years. The relationship between depression and cognitive dysfunction, and treatment are discussed elsewhere [71]. Depression impacts' on all aspects of life and can amplify symptoms, leading to further limitation in function, and interferes with disease management [102]. Major depressive disorder is linked to objective cognitive difficulties (attention and memory) [103].

Selective serotonin reuptake inhibitors are widely used to treat depression in rehabilitation. One study $(n=630)$ compared CBT, the antidepressant Sertraline, and group psychotherapy [104]. CBT and Sertraline were more efficacious 
than group therapy, and improvement in depressive symptoms persisted at 6-month followup. Symptoms of depression also improved in persons who received an alternate approach-an eight-week telephone cognitive behavioural intervention compared to usual care [105]. This approach was adapted to address barriers such as transportation and access pwMS. Exercise improves mood, fatigue and QoL $[105,106]$ and is as effective as standard antidepressant medication and psychotherapy [107].

Other approaches to treat depression include behaviour activation (which treats depression by increasing access to positive reinforcement and decreasing frequency and intensity of aversive events and consequences) [108] and interpersonal therapy-an evidence based approach that focus' on role disputes and role transitions as a framework for therapy [109].

Psychosocial issues include inability to cope (patient and family), stress, financial considerations, and marital discord. A recent Australian study outlined factors impacting on MS caregivers in a community setting [110]. More strain was reported in caregivers caring for pwMS with depression, anxiety, and stress levels, with a poorer QoL for both the carer and care recipient. Education and support, stress management, and coping skills can positively influence health and wellbeing and may require clinical psychology and psychiatry. Neuropsychological counselling improved insight and social skills training compared with standard counselling, in reducing disinhibition and socially aggressive behaviour especially in cognitively impaired pwMS [111].

5.1.8. General Reconditioning and Ambulation. Reduced physical activity and exercise due to MS limitations have been discussed elsewhere [112]. Causal factors include decreased muscle strength, aerobic capacity, maximal vital capacity, and increase in neuromuscular tension, fatigue, anxiety, and depression. Exercise programs do not alter the MS disease course but do prevent secondary effects of inactivity and improve fatigue and sense of well-being. An integrated exercise program incorporates: a daily passive range of motion, an active range of motion with gravity eliminated or against gravity as allowed by strength, and specific muscle training (three sets of 10 repetitions) is recommended for focal weakness, when fatigue and heat sensitivity are issues $[112,113]$. Active exercise for 20-30 minutes 3 times per week, with a 5 minute warmup and cool-down, stretching for lower limbs and back is effective [112], while aerobic exercises for cardiovascular fitness are important for overweight persons [114].

Gait is impaired by weakness, spasticity, incoordination, balance, fatigue, and visual disturbances. For ambulation, a graded program should improve trunk control and balance, followed by normalizing tone, flexibility, and range of motion and then strength. Graded sitting and standing tolerance program and tilt table routine prior to gait training may be required. Proprioceptive, tactile, and visual cues are also helpful. Specific ambulation aids (elbow crutches, walking frames, and ankle foot orthoses) and mobility devices (wheel chairs and scooters) can decrease energy expenditure and improve safety and endurance [115]. A person's strength, motor control, cognition, and emotional response are all considered prior to prescription. Wheelchairs are customized for each person, such as appropriate seating, posture support, tilt in space mechanism, and manipulation of components (arm rests, foot plates). Scooters assist those with ataxia and fatigue. Weighted wrist cuffs and walkers may help dampen tremors [116].

5.1.9. Activities of Daily Living. Improvement in functional independence and maintenance is a key rehabilitation goal. Principles of occupational therapy (OT) in MS have been previously discussed [117]. OT was effective in improving function in pwMS, using retraining techniques for personal, domestic, and community tasks, mainly in inpatient settings [34]. However, in a recent systematic review [31] patient education and energy conservation strategies in MS were found to be inconclusive due to methodological weakness of included studies. OT should concentrate on activities that pwMS would use in practice, rather than on activities that people may not value because of environmental or behavioural circumstances [85].

5.1.10. Driving. Although a recent study did not find excessive risk for fatal road accidents in pwMS [118], many issues impact on driving, especially cognitive and perceptual considerations [119]. Driving assessments may be required based on each individual's deficits. In persons with PPMS, if there are concerns, then a driving assessment by the occupational therapist is recommended. Fatigue-related issues due to MS may impact on the ability of the pwMS to drive for 45 minutes without a break-this has implications for holding a full driving license (Australia). Restrictions such as driving during day time only (poor night vision) or driving in localized area may be required. For more severely affected individuals, other specialized driving adaptations such as hand brakes, use of spinner knob on driving wheel, extra rear view mirrors, and motorized pulleys for folding and storage of wheelchairs may be needed.

5.1.11. Employment. An estimated 65\% of pwMS were working at the time of their diagnosis, and between $25 \%$ and $35 \%$ of these persons remain in work force 5-10 years of diagnosis [120]. Fatigue, urinary urgency and incontinence, and visual and mobility issues are the main barriers for continued employment. Many pwMS leave workforce prematurely, or on advice of a well-meaning health care provider or family member. Rehabilitation input may assist in continued employment. Reasonable accommodations for MS include flexible working hours, work at home options, transportation, accessible work environment (bathroom, desk), memory aids (planners and diaries), vision aids (voice recognition software), and air-conditioning. Returnto-work programs are customized, graded (gradual increase in working hours), or altered to suit the individual with MS [121]. These programs are coordinated by the Vocational Rehabilitation Services, in collaboration with the employee, employer and the treating rehabilitation team. Vocational rehabilitation interventions for pwMS focus on job retention 
strategies rather than retraining for new jobs. There are a very limited number of high-quality studies at present that address the efficacy of vocational rehabilitation in the MS population. A recent review, therefore, found insufficient evidence as yet to support vocational rehabilitation in pwMS [122].

\section{Summary}

The multiple concurrent MS-related physical, cognitive, emotional, and social issues make rehabilitation challenging in persons with PPMS. Rehabilitation measures do not alter the course of MS disease. The overriding principle in setting goals for a pwMS is to maximize functional independence and safety, minimize complications and problems that result from decreased mobility, compensate for loss of function, and improve quality of life. With disease progression a "neuropalliative" approach is required. Rehabilitation should be viewed as an ongoing process to anticipate problems and to maintain and restore maximum function and QoL for persons with PPMS.

\section{Conflict of Interests}

The authors report no conflict of interests.

\section{References}

[1] Programme for Neurological Diseases and Neurosciences Department of Mental Health and Substance Abuse, Atlas: Country Resources for Neurological Disorders: Results of a Collaborative Study of World Health Organization and World Federation of Neurology, World Health Organization, Geneva, Switzerland, 2004.

[2] N. G. Torkildsen, S. A. Lie, J. H. Aarseth, and K. M. Myhr, "Survival and cause of death in multiple sclerosis: results from a 50-year follow-up in Western Norway," Multiple Sclerosis, vol. 14, no. 9, pp. 1191-1198, 2008.

[3] F. Khan, T. McPhail, C. Brand, L. Turner-Stokes, and T. Kilpatrick, "Disability profile and quality of life in multiple sclerosis in an Australian community cohort," International Journal of Rehabilitation Research, vol. 29, no. 2, pp. 87-96, 2006.

[4] R. Rovaris, E. Judica, J. Sastre-Garriga et al., "Large-scale, multicentre, quantitative MRI study of brain and cord damage in primary progressive multiple sclerosis," Multiple Sclerosis, vol. 14, no. 4, pp. 455-466, 2008.

[5] X. Montalban, "Primary progressive multiple sclerosis," Current Opinion in Neurology, vol. 18, no. 3, pp. 261-266, 2005.

[6] D. Bar-Zohar, A. Agosta, D. Goldstaub, and M. Filippi, "Magnetic resonance imaging metrics and their correlation with clinical outcomes in multiple sclerosis: a review of the literature and future perspectives," Multiple Sclerosis, vol. 14, no. 6, pp. 719-727, 2008.

[7] L. Ramió-Torrentà, J. Sastre-Garriga, G. T. Ingle et al., "Abnormalities in normal appearing tissues in early primary progressive multiple sclerosis and their relation to disability: a tissue specific magnetisation transfer study," Journal of Neurology, Neurosurgery and Psychiatry, vol. 77, no. 1, pp. 4045, 2006.
[8] A. Kutzelnigg, C. F. Lucchinetti, C. Stadelmann et al., "Cortical demyelination and diffuse white matter injury in multiple sclerosis," Brain, vol. 128, no. 11, pp. 2705-2712, 2005.

[9] M. Rovaris, M. Bozzali, G. Santuccio et al., "In vivo assessment of the brain and cervical cord pathology of patients with primary progressive multiple sclerosis," Brain, vol. 124, no. 12, pp. 2540-2549, 2001.

[10] M. Bieniek, D. R. Altmann, G. R. Davies et al., "Cord atrophy separates early primary progressive and relapsing remitting multiple sclerosis," Journal of Neurology, Neurosurgery and Psychiatry, vol. 77, no. 9, pp. 1036-1039, 2006.

[11] C. H. Polman, S. C. Reingold, G. Edan et al., "Diagnostic criteria for multiple sclerosis: 2005 revisions to the "McDonald criteria",' Annals of Neurology, vol. 58, no. 6, pp. 840-846, 2005.

[12] C. H. Polman, S. C. Reingold, B. Banwell et al., "Diagnostic criteria for multiple sclerosis: 2010 revisions to the McDonald criteria," Annals of Neurology, vol. 69, no. 2, pp. 292-302, 2011.

[13] N. Grytten, S. A. Torkildsen, J. H. Aarseth, H. Nyland, and K. M. Myhr, "Survival and cause of death in multiple sclerosis: results from a 50-year follow-up in Western Norway," Multiple Sclerosis, vol. 14, no. 9, pp. 1191-1198, 2008.

[14] D. A. Cottrell, M. Kremen-chutzky, G. P. A. Rice et al., "The natural history of multiple sclerosis: a geographically based study. 5 . The clinical features and natural history of primary progressive multiple sclerosis," Brain, vol. 122, no. 4, pp. 625639, 1999.

[15] World Health Organization (WHO), The International Classification of Functioning, Disability and Health (ICF), World Health Organization, Geneva, Switzerland, 2001.

[16] S. A. Steins, B. O’Brien, and M. Young, "The person, disablement and the process of rehabilitation," in PM\& $R$ Secrets, B. O'Young, M. Young, and S. A. Steins, Eds., pp. 1-8, Hanley \& Belfus, Philadelphia, Pa, USA, 1997.

[17] J. S. Wolinsky, P. A. Narayana, P. O’Connor et al., "Glatiramer acetate in primary progressive multiple sclerosis: results of a multinational, multicenter, double-blind, placebo-controlled trial," Annals of Neurology, vol. 61, no. 1, pp. 14-24, 2007.

[18] F. Khan and J. F. Pallant, "Use of the International Classification of Functioning, Disability and Health (ICF) to identify preliminary comprehensive and brief core sets for multiple sclerosis," Disability and Rehabilitation, vol. 29, no. 3, pp. 205-213, 2007.

[19] F. Khan and J. F. Pallant, "Use of International Classification of Functioning, Disability and Health (ICF) to describe patient-reported disability in multiple sclerosis and identification of relevant environmental factors," Journal of Rehabilitation Medicine, vol. 39, no. 1, pp. 63-70, 2007.

[20] G. H. Kraft and J. Y. Cui, "Multiple sclerosis," in Physical Medicine and Rehabilitation: Principles and Practice, J. A. Delisa, Ed., pp. 1753-1769, 4th edition, 2005.

[21] D. T. Wade, Measurement in Neurological Rehabilitation, Oxford University Press, 1992.

[22] J. C. Hobart, D. L. Lamping, J. A. Freeman et al., "Evidence based measurement: which disability scale for neurologic rehabilitation?” Neurology, vol. 57, no. 4, pp. 639-644, 2001.

[23] D. A. Rossiter, A. Edmondson, R. Al-Shahi et al., "Integrated pathways in multiple sclerosis: completing the audit cycle," Multiple Sclerosis, vol. 4, no. 2, pp. 85-89, 1998.

[24] F. Khan, J. F. Pallant, and L. Turner-Stokes, "Use of goal attainment scaling in inpatient rehabilitation for persons 
with multiple sclerosis," Archives of Physical Medicine and Rehabilitation, vol. 89, no. 4, pp. 652-659, 2008.

[25] Royal College of Physicians, National Council for Palliative care. British Society of Rehabilitation Medicine, Concise Guidance to Good Practice Series, vol. 10, Royal College of Physicians, London, UK, 2008.

[26] National Institute for Clinical Excellence [NICE], "Multiple Sclerosis: Management of multiple sclerosis in primary and secondary care. Clinical Guidelines -8," NICE, ISBN: 1842574426, 2003, http://www.nice.org.uk.

[27] Department of Health, "The National Service Framework [NSF] for Long -term Conditions," DoH, UK, 2005.

[28] A. J. Thompson, "Symptomatic management and rehabilitation in multiple sclerosis," Journal of Neurology, Neurosurgery and Psychiatry, vol. 71, no. 2, pp. 22-27, 2001.

[29] F. Khan, L. Turner-Stokes, L. Ng, and T. Kilpatrick, "Multidisciplinary rehabilitation for adults with multiple sclerosis," The Cochrane Database of Systematic Reviews, no. 2, Article ID CD006036, 2007.

[30] M. B. Reitberg, D. Brooks, B. M. J. Utidehaag, and G. Kwakkel, "Exercise therapy for multiple sclerosis," Cochrane Database of Systematic Review, no. 3, Article ID CD003980, 2004.

[31] E. M. Steultjens, J. Dekker, L. M. Bouter, M. Cardol, J. C. van de Nes, and C. H. van den Ende, "Occupational therapy for multiple sclerosis," The Cochrane Database of Systematic Reviews, no. 3, p. CD003608, 2003.

[32] N. A. Baker and L. Tickle-Degnen, "The effectiveness of physical, psychological, and functional interventions in treating clients with multiple sclerosis: a meta-analysis," American Journal of Occupational Therapy, vol. 55, no. 3, pp. 324-331, 2001.

[33] P. W. Thomas, S. Thomas, C. Hillier, K. Galvin, and R. Baker, "Psychological interventions for multiple sclerosis," The Cochrane Database of Systematic Reviews, no. 1, p. CD004431, 2006.

[34] F. Khan, J. F. Pallant, C. Brand, and T. J. Kilpatrick, "Effectiveness of rehabilitation intervention in persons with multiple sclerosis: a randomised controlled trial," Journal of Neurology, Neurosurgery and Psychiatry, vol. 79, no. 11, pp. 1230-1235, 2008.

[35] L. Costelloe, K. O’Rourke, H. Kearney et al., “The patient knows best: significant change in the physical component of the Multiple Sclerosis Impact Scale (MSIS-29 physical)," Journal of Neurology, Neurosurgery and Psychiatry, vol. 78, no. 8, pp. 841-844, 2007.

[36] F. Khan, J. F. Pallant, N. Zhang, and L. Turner-Stokes, "Clinical practice improvement approach in multiple sclerosis: a pilot study," International Journal of Rehabilitation Research, vol. 33, no. 3, pp. 238-247, 2010.

[37] L. Turner-Stokes and A. Shaw, "The Northwick Park Therapy Dependency Score (NPTDA): development, preliminary evaluation and application," A report for the Department of Health Project Grant 030/0066, Kings College, London, UK, 2006.

[38] F. Khan, L. Turner-Stokes, T. Stevermuer, and F. Simmonds, "Multiple sclerosis rehabilitation outcomes: lessons learnt from an Australian casemix dataset," Multiple Sclerosis, vol. 15, no. 7, pp. 869-875, 2009.

[39] Department of Health: long term conditions NSF Team, "The National Services Framework for Long Term Neurological Conditions," Department of Health, UK, 2005.
[40] D. C. Traue and J. R. Ross, "Palliative care in non-malignant diseases," Journal of the Royal Society of Medicine, vol. 98, no. 11, pp. 503-506, 2005.

[41] L. Turner-Stokes, N. Sykes, E. Silber, A. Khatri, L. Sutton, and E. Young, "From diagnosis to death: exploring the interface between neurology, rehabilitation and palliative care in managing people with long-term neurological conditions," Clinical Medicine, vol. 7, no. 2, pp. 129-136, 2007.

[42] Paralysed Veterans of America, "Multiple Sclerosis Council for Clinical Practice Guidelines. Fatigue and Multiple Sclerosis. Evidence based management strategies for fatigue," in Multiple Sclerosis, Paralysed Veterans of America, 1998.

[43] S. R. Schwid, M. Covington, B. M. Segal, and A. D. Goodman, "Fatigue in multiple sclerosis: current understanding and future directions," Journal of Rehabilitation Research and Development, vol. 39, no. 2, pp. 211-224, 2002.

[44] J. Iriarte, G. Katsamakis, and P. de Castro, "The Fatigue Descriptive Scale (FDS): a useful tool to evaluate fatigue in multiple sclerosis," Multiple Sclerosis, vol. 5, no. 1, pp. 10-16, 1999.

[45] J. D. Fisk, P. G. Ritvo, L. Ross, D. A. Haase, T. J. Marrie, and W. F. Schlech, "Measuring the functional impact of fatigue: initial validation of the fatigue impact scale," Clinical Infectious Diseases, vol. 18, supplement 1, pp. S79-S83, 1994.

[46] J. E. Schwartz, L. Jandorf, and L. B. Krupp, "The measurement of fatigue: a new instrument," Journal of Psychosomatic Research, vol. 37, no. 7, pp. 753-762, 1993.

[47] L. B. Krupp, N. G. LaRocca, J. Muir-Nash, and A. D. Steinberg, "The fatigue severity scale. Application to patients with multiple sclerosis and systemic lupus erythematosus," Archives of Neurology, vol. 46, no. 10, pp. 1121-1123, 1989.

[48] W. S. MacAllister and L. B. Krupp, "Multiple sclerosis related fatigue," Physical Medicine and Rehabilitation Clinics of North America, vol. 16, no. 2, pp. 483-502, 2005.

[49] A. E. Miller, F. D. Lublin, and P. K. Coyle, Multiple Sclerosis in Clinical Practice, Martin Dunitz, Taylor and Francis, UK, 2003.

[50] J. E. Freal, G. H. Kraft, and J. K. Coryell, "Symptomatic fatigue in multiple sclerosis," Archives of Physical Medicine and Rehabilitation, vol. 65, no. 3, pp. 135-138, 1984.

[51] J. F. Kurtzke, "Rating neurologic impairment in multiple sclerosis: an Expanded Disability Status Scale (EDSS)," Neurology, vol. 33, no. 11, pp. 1444-1452, 1983.

[52] A. Solari, B. Uitedehaag, G. Guiliani et al., "Aminopridines for symptomatic treatment in multiple sclerosis," The Cochrane Database of Systematic Reviews, no. 4, Article ID CD001330, 2002.

[53] F. Khan, J. F. Pallant, T. L. Shea, and M. Whishaw, "Multiple sclerosis: prevalence and factors impacting bladder and bowel function in an Australian community cohort," Disability and Rehabilitation, vol. 31, no. 19, pp. 1567-1576, 2009.

[54] F. Khan, J. F. Pallant, J. I. Pallant, C. Brand, and T. J. Kilpatrick, "A randomised controlled trial: outcomes of bladder rehabilitation in persons with multiple sclerosis," Journal of Neurology, Neurosurgery and Psychiatry, vol. 81, no. 9, pp. 1033-1038, 2010.

[55] M. de Sèze, A. Ruffion, P. Denys, P. A. Joseph, and B. Perrouin-Verbe, "The neurogenic bladder in multiple sclerosis: review of the literature and proposal of management guidelines," Multiple Sclerosis, vol. 13, no. 7, pp. 915-928, 2007.

[56] E. Munteis, M. Andreu, M. J. Téllez, D. Mon, A. Ois, and J. Roquer, "Anorectal dysfunction in multiple sclerosis," Multiple Sclerosis, vol. 12, no. 2, pp. 215-218, 2006. 
[57] F. Khan, J. F. Pallant, L. Ng, and M. Whishaw, "Sexual dysfunction in multiple sclerosis," Sexuality and Disability, vol. 29, pp. 101-111, 2011.

[58] R. D. Penn, S. M. Savoy, D. Corcos et al., "Intrathecal baclofen for severe spinal spasticity," The New England Journal of Medicine, vol. 320, no. 23, pp. 1517-1521, 1989.

[59] B. Ashworth, "Preliminary trial of carisoprodol in multiple sclerosis," Practitioner, vol. 192, pp. 540-542, 1964.

[60] A. Haugh, A. Pandyan, and G. Johnson, "A systematic review of the Tardieu scale for the measurement of spasticity," Disability and Rehabilitation, vol. 28, no. 15, pp. 899-907, 2006.

[61] A. D. Goodman, T. R. Brown, K. R. Edwards et al., "A phase 3 trial of extended release oral dalfampridine in multiple sclerosis," Annals of Neurology, vol. 68, no. 4, pp. 494-502, 2010.

[62] A. D. Goodman, T. R. Brown, L. B. Krupp et al., "Sustainedrelease oral fampridine in multiple sclerosis: a randomised, double-blind, controlled trial," The Lancet, vol. 373, no. 9665, pp. 732-738, 2009.

[63] L. R. Mehata, M. P. McDermott, A. D. Goodman et al., "A randomised trial of mematine as treatment for spasticity in multiple sclerosis," Multiple Sclerosis, vol. 16, no. 2, pp. 248251, 2010.

[64] I. Mohammed and A. Hussain, "Intrathecal baclofen withdrawal syndrome- a life-threatening complication of baclofen pump: a case report," BMC Clinical Pharmacology, vol. 4, no. 6, 2005.

[65] N. Hyman, M. Barnes, B. Bhakta et al., "Botulinum toxin (Dysport ${ }^{\circledR}$ ) treatment of hip adductor spasticity in multiple sclerosis: a prospective, randomised, double blind, placebo controlled, dose ranging study," Journal of Neurology Neurosurgery and Psychiatry, vol. 68, no. 6, pp. 707-712, 2000.

[66] S. E. Lord, D. T. Wade, and P. W. Halligan, "A comparison of two physiotherapy treatment approaches to improve walking in multiple sclerosis: a pilot randomized controlled study," Clinical Rehabilitation, vol. 12, no. 6, pp. 77-86, 1998.

[67] R. J. Mills, L. Yap, and C. A. Young, "Treatment for ataxia in multiple sclerosis," The Cochrane Database of Systematic Reviews, no. 1, Article ID CD005029, 2007.

[68] A. Beric, "Central pain and dysesthesia syndrome," Neurologic Clinics, vol. 16, no. 4, pp. 899-918, 1998.

[69] J. Boivie, "Central pain," in Textbook of Pain, P. D. Wall and R. Melzack, Eds., pp. 879-914, Churchill Livingstone, New York, NY, USA, 1999.

[70] B. C. Hans, W. D. Willis, and C. E. Hulsebosch, "Temporal plasticity of dorsal horn somatosensory neurons after acute and chronic spinal cord hemisection in rat," Brain Research, vol. 970, no. 1-2, pp. 238-241, 2003.

[71] D. M. Ehde, T. L. Osborne, and M. P. Jensen, "Chronic pain in persons with multiple sclerosis," Physical Medicine and Rehabilitation Clinics of North America, vol. 16, no. 2, pp. 503-512, 2005.

[72] F. Khan and J. Pallant, "Multiple sclerosis: the prevalence of chronic pain-related disability and psychological factors impacting quality of life in an Australian community cohort," Journal of Pain, vol. 8, no. 8, pp. 14-23, 2007.

[73] C. J. Archibald, P. J. McGrath, P. G. Ritvo et al., "Pain prevalence, severity and impact in a clinic sample of multiple sclerosis patients," Pain, vol. 58, no. 1, pp. 89-93, 1994.

[74] F. Khan, J. F. Pallant, B. Amatya et al., "Cognitive-behavioral classifications of chronic pain in patients with multiple sclerosis," International Journal of Rehabilitation Research, vol. 34, no. 3, pp. 235-242, 2011.
[75] A. Burke-Doe, "Pain management," in Neurological Rehabilitation, D. A. Umphred, Ed., Mosby Elsivier, St Louis, Mo, USA, 5th edition, 2007.

[76] M. K. Houtchens, J. R. Richert, A. Sami, and J. W. Rose, "Open label gabapentin treatment for pain in multiple sclerosis," Multiple Sclerosis, vol. 3, no. 4, pp. 250-253, 1997.

[77] J. Al Smadi, C. Campbell, L. Nicholl et al., "A pilot investigation of the hypoalgesic effects of transcutaeous electrical stimulation upon lower back in people with multiple sclerosis," Clinical Rehabilitation, vol. 17, no. 7, pp. 742-749, 2003.

[78] L. Frighetto, A. A. de Salles, Z. A. Smith, B. Goss, M. Selch, and T. Solberg, "Noninvasive linear accelerator radiosurgery as the primary treatment for trigeminal neuralgia," Neurology, vol. 62, no. 4, pp. 660-662, 2004.

[79] D. J. Rog, T. J. Nurmikko, T. Friede, and C. A. Young, "Randomized, controlled trial of cannabis-based medicine in central pain in multiple sclerosis," Neurology, vol. 65, no. 6, pp. 812-819, 2005.

[80] C. Solaro, M. Boehmker, and P. Tanganelli, "Pregabalin for treating paroxysmal painful symptoms in multiple sclerosis," Journal of Neurology, vol. 256, no. 10, pp. 1773-1774, 2009.

[81] P. Gray, "Pregabalin in the management of central neuropathic pain," Expert Opinion on Pharmacotherapy, vol. 8, no. 17, pp. 3037-3041, 2007.

[82] R. K. Heaton, "Neoropsychologicl findings in relapsingremitting and chronic progressivd multiple sclerosis," Journal of Consulting and Clinical Psychology, vol. 53, no. 1, pp. 103110, 1985.

[83] S. M. Rao, G. J. Leo, L. Bernardin, and F. Unverzagt, "Cognitive dysfunction in multiple sclerosis. I. Frequency, patterns, and prediction," Neurology, vol. 41, no. 5, pp. 685691, 1991.

[84] M. Pepping and D. M. Ehde, "Neuropsychological evaluation and treatment of multiple sclerosis: the importance of a neuro-rehabilitation focus," Physical Medicine and Rehabilitation Clinics of North America, vol. 16, no. 2, pp. 411-436, 2005.

[85] D. Frankel, "Multiple sclerosis," in Neurological Rehabilitation, D. A. Umphred, Ed., pp. 709-731, Mosby Elsievier, St Louis, Mo, USA, 5th edition, 2007.

[86] G. M. Franklin, L. M. Nelson, C. M. Filley, and R. K. Heaton, "Cognitive loss in multiple sclerosis," Archives of Neurology, vol. 46, no. 2, pp. 162-169, 1989.

[87] Y. Goverover, M. Basso, H. Wood et al., "Examining the benefits of combining two learning strategies on recall of functional information in persons with multiple sclerosis," Multiple Sclerosis. In press.

[88] A. M. Plohmann, L. Kappos, W. Ammann et al., "Computer assisted retraining of attentional impairments in patients with multiple sclerosis," Journal of Neurology Neurosurgery and Psychiatry, vol. 64, no. 4, pp. 455-462, 1998.

[89] M. W. Geisler, M. Sliwinski, P. K. Coyle, D. M. Masur, C. Doscher, and L. B. Krupp, "The effects of amantadine and pemoline on cognitive functioning in multiple sclerosis," Archives of Neurology, vol. 53, no. 2, pp. 185-188, 1996.

[90] A. Weinstein, S. R. Schwid, R. B. Schiffer, M. P. McDermott, D. W. Giang, and A. D. Goodman, "Neuropsychologic status in multiple sclerosis after treatment with glatiramer actetate (Copaxone)," Archives of Neurology, vol. 56, no. 3, pp. 319324, 1999.

[91] J. F. Lovera, E. Frohman, T. R. Brown et al., "Memantine for cognitive impairment in multiple sclerosis: a randomized 
placebo-controlled trial," Multiple Sclerosis, vol. 16, no. 6, pp. 713-723, 2010.

[92] L. B. Krupp, C. Christodoulou, P. Melville et al., "Multicenter randomized clinical trial of donepezil for memory impairment in multiple sclerosis," Neurology, vol. 76, no. 17, pp. 1500-1507, 2011.

[93] K. Aronson, E. Goldenberg, and G. Cleghorn, "Sociodemographic characteristics and health status of persons with multiple sclerosis and their caregivers," MS Management, vol. 3, no. 1, pp. 5-15, 1996.

[94] M. Starck, H. Albrecht, W. Pöllmann, A. Straube, and M. Dieterich, "Drug therapy for acquired pendular nystagmus in multiple sclerosis," Journal of Neurology, vol. 244, no. 1, pp. 9-16, 1997.

[95] R. M. Merson and M. I. Rolnick, "Speech-language pathology and dysphagia in multiple sclerosis," Physical Medicine and Rehabilitation Clinics of North America, vol. 9, no. 3, pp. 6371, 1998

[96] S. Sapir, A. A. Pawlas, L. O. Ramig, E. Seeley, C. Fox, and J. Corboy, "Effects of intensive phonatory-respiratory treatment (LSVT) on voice in two individuals with multiple sclerosis," Journal of Medical Speech-Language Pathology, vol. 9, no. 2, pp. 141-151, 2001.

[97] L. Hartelius and L. Nord, "Speech modification in dysarthria associated with multiple sclerosis: an intervention based on vocal efficiency, contrastive stress, and verbal repair strategies," Journal of Medical Speech-Language Pathology, vol. 5, no. 2, pp. 113-140, 1997.

[98] F. J. Thomas and C. M. Wiles, "Dysphagia and nutritional status in multiple sclerosis," Journal of Neurology, vol. 246, no. 8, pp. 677-682, 1999.

[99] P. Calcagno, G. Ruoppolo, M. G. Grasso, M. de Vincentiis, and S. Paolucci, "Dysphagia in multiple sclerosisprevalence and prognostic factors," Acta Neurologica Scandinavica, vol. 105, no. 1, pp. 40-43, 2002.

[100] A. de Pauw, E. Dejaeger, B. D’hooghe, and H. Carton, "Dysphagia in multiple sclerosis," Clinical Neurology and Neurosurgery, vol. 104, no. 4, pp. 345-351, 2002.

[101] S. B. Patten, C. A. Beck, J. V. A. Williams, C. Barbui, and L. M. Metz, "Major depression in multiple sclerosis: a populationbased perspective," Neurology, vol. 61, no. 11, pp. 1524-1527, 2003.

[102] W. Katon and P. Ciechanowski, "Impact of major depression on chronic medical illness," Journal of Psychosomatic Research, vol. 53, no. 4, pp. 859-863, 2002.

[103] R. H. B. Benedict, J. S. Fischer, C. J. Archibald et al., "Minimal neuropsychological assessment of MS patients: a consensus approach," Clinical Neuropsychologist, vol. 16, no. 3, pp. 381$397,2002$.

[104] D. C. Mohr, A. C. Boudewn, D. E. Goodin et al., "Comparative outcomes for individual cognitive behaviour therapy, supportive espressive group psychotherapy, and setraline for the treatment of depression in multiple sclerosis," Journal of Consulting and Clinical Psychology, vol. 69, no. 6, pp. 942949, 2001.

[105] D. C. Mohr, W. Likosky, A. Bertagnolli et al., "Telephoneadministered cognitive-behavioral therapy for the treatment of depressive symptoms in multiple sclerosis," Journal of Consulting and Clinical Psychology, vol. 68, no. 2, pp. 356$361,2000$.

[106] A. L. Brosse, E. S. Sheets, H. S. Lett, and J. A. Blumenthal, "Exercise and the treatment of clinical depression in adults: recent findings and future directions," Sports Medicine, vol. 32, no. 12, pp. 741-760, 2002.
[107] E. W. Martinsen, "Physical activity and depression: clinical experience," Acta Psychiatrica Scandinavica, vol. 377, pp. 2327, 1994.

[108] D. R. Hopko, C. W. Lejuez, K. J. Ruggiero, and G. H. Eifert, "Contemporary behavioral activation treatments for depression: procedures, principles, and progress," Clinical Psychology Review, vol. 23, no. 5, pp. 699-717, 2003.

[109] G. L. Klerman and M. M. Weissmann, "Interpersonal psychotherapy (IPT) and drugs in the treatment of depression," Pharmacopsychiatry, vol. 20, no. 1, pp. 3-7, 1987.

[110] F. Khan, J. Pallant, and C. Brand, "Caregiver strain and factors associated with caregiver self-efficacy and quality of life in a community cohort with multiple sclerosis," Disability and Rehabilitation, vol. 29, no. 16, pp. 1241-1260, 2007.

[111] R. H. B. Benedict, A. Shapiro, R. Priore, C. Miller, F. Munschauer, and L. Jacobs, "Neuropsychological counseling improves social behavior in cognitively-impaired multiple sclerosis patients," Multiple Sclerosis, vol. 6, no. 6, pp. 391396, 2000.

[112] T. R. Brown and G. H. Kraft, "Exercise and rehabilitation for individuals with multiple sclerosis," Physical Medicine and Rehabilitation Clinics of North America, vol. 16, no. 2, pp. 513-556, 2005.

[113] A. T. White, "Exercise and MS: challenges and opportunities," Multiple Sclerosis Quality Report, vol. 23, no. 1, pp. 18-20, 2004.

[114] D. C. Hewson, M. A. Phillips, K. E. Simpson, P. Drury, and M. A. Crawford, "Food intake in multiple sclerosis," Human Nutrition. Applied nutrition, vol. 38, no. 5, pp. 355-367, 1984.

[115] G. H. Kraft, "Foreword," Physical Medicine and Rehabilitation Clinics of North America, vol. 9, no. 3, pp. 11-13, 1998.

[116] M. L. Aisen, A. Arnold, I. Baiges, S. Maxwell, and M. Rosen, "The effect of mechanical damping loads on disabling action tremor," Neurology, vol. 43, no. 7, pp. 1346-1350, 1993.

[117] M. M. LaBan, T. Martin, J. Pechur, and S. Sarnacki, "Physical and occupational therapy in the treatment of patients with multiple sclerosis," Physical Medicine and Rehabilitation Clinics of North America, vol. 9, no. 3, pp. 603-614, 1998.

[118] H. Bronnum-Hansen, H. Hansen, N. Kock-Henriksen, and E. Stenager, "Fatal accidents among Danes with multiple sclerosis," Multiple Sclerosis, vol. 12, pp. 329-332, 2006.

[119] M. T. Schulthesis, E. Garay, S. R. Millis, and J. DeLuca, "Motor vehicle crashes and violations among drivers with multiple sclerosis," Archives of Physical Medicine and Rehabilitation, vol. 83, no. 8, pp. 1175-1178, 2002.

[120] P. Rumrill, Employment Issues and Multiple Sclerosis, Demos Publications, New York, NY, USA, 1996.

[121] K. L. Johnson and R. T. Fraser, "Mitigating the impact of multiple sclerosis on employment," Physical Medicine and Rehabilitation Clinics of North America, vol. 16, no. 2, pp. 771-783, 2005.

[122] F. Khan, L. Ng, and L. Turner-Stokes, "Effectiveness of vocational rehabilitation intervention on the return to work and employment of persons with multiple sclerosis," The Cochrane Database of Systematic Reviews, no. 1, Article ID CD007256, 2009. 


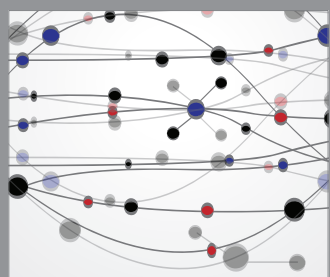

The Scientific World Journal
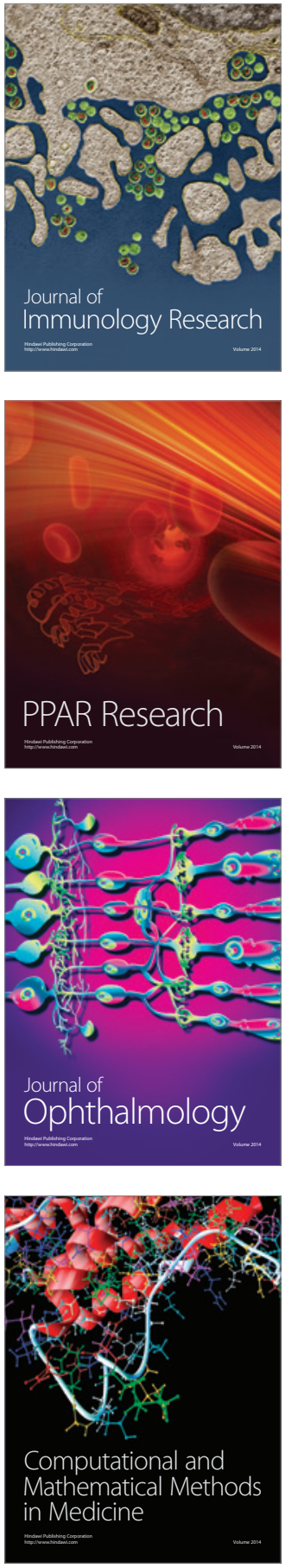

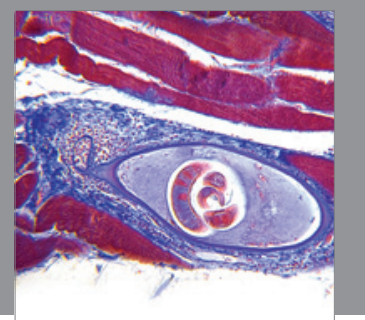

Gastroenterology

Research and Practice
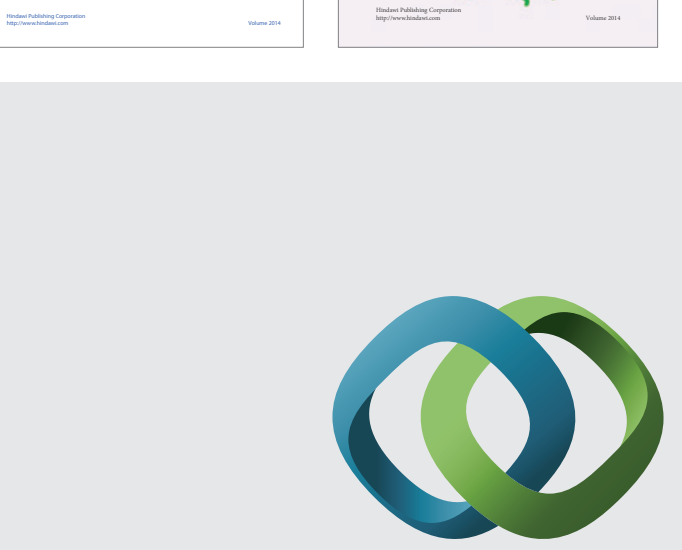

\section{Hindawi}

Submit your manuscripts at

http://www.hindawi.com
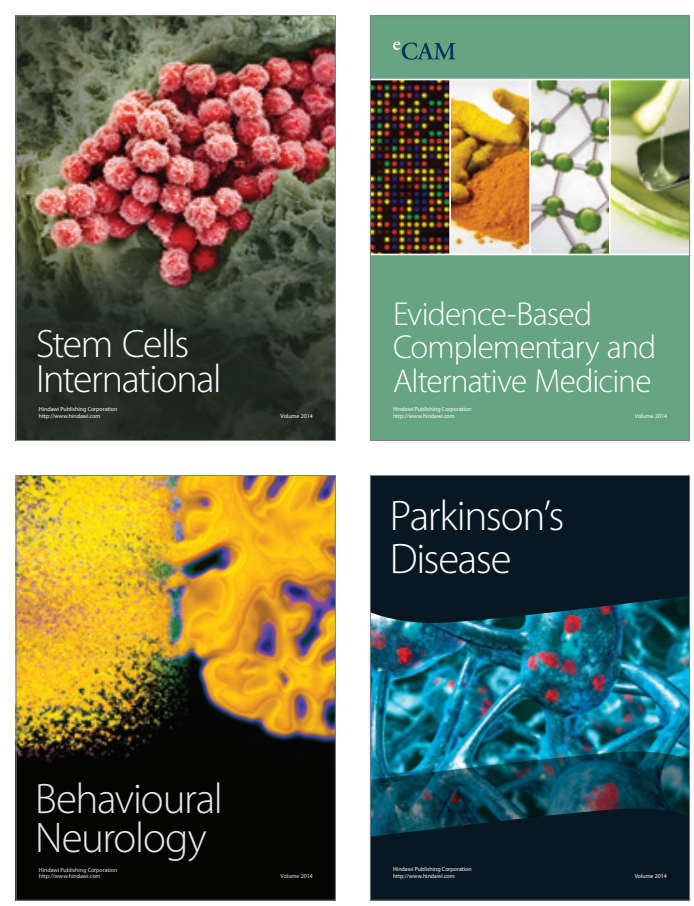

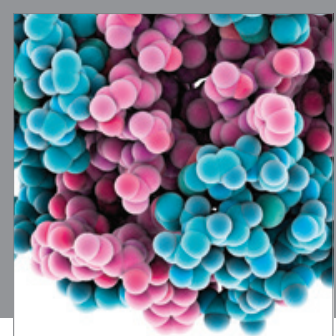

Journal of
Diabetes Research

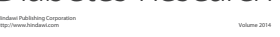

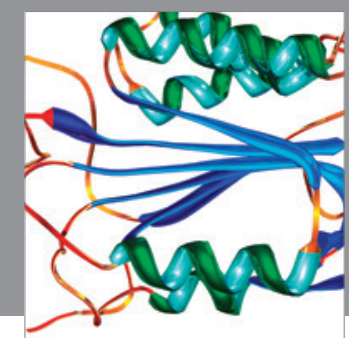

Disease Markers
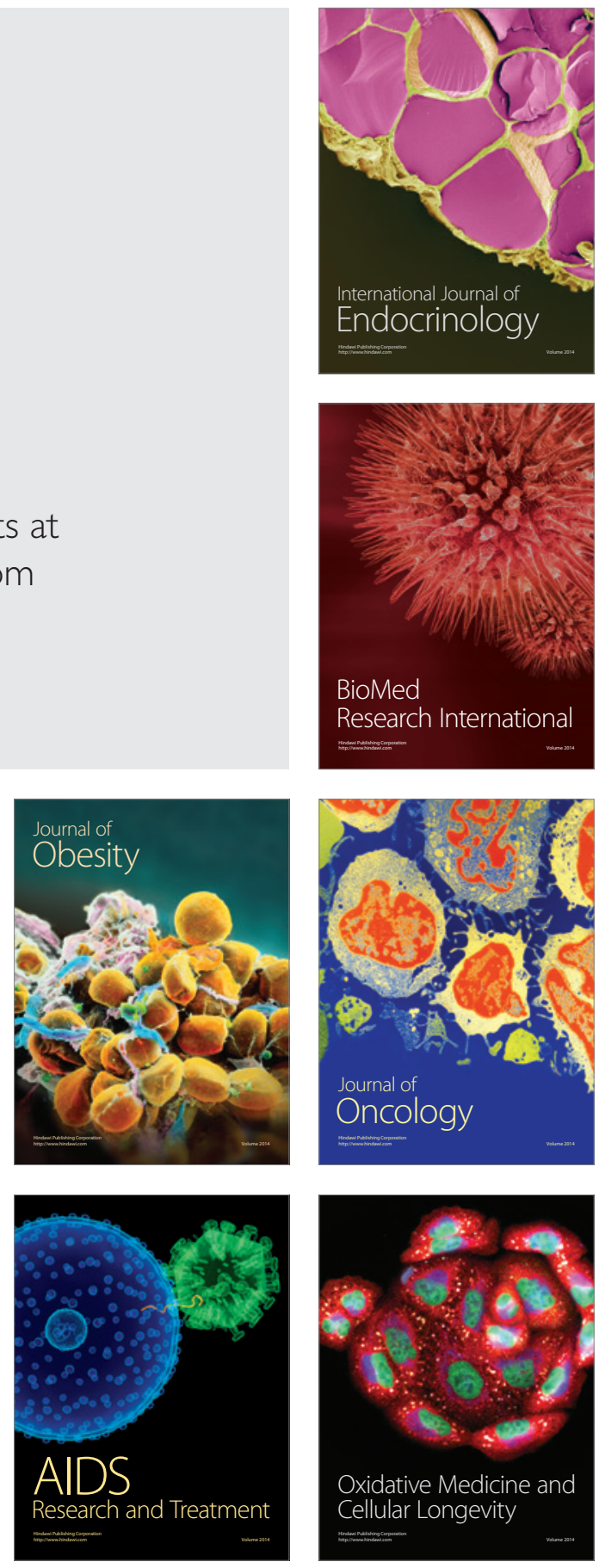